Portland State University

PDXScholar

Dissertations and Theses

Dissertations and Theses

Spring 6-6-2013

\title{
Public Opinion and the Oregon Death with Dignity
}

Act

Peggy Jo Ann Sandeen

Portland State University

Follow this and additional works at: https://pdxscholar.library.pdx.edu/open_access_etds

Part of the Medicine and Health Commons, and the Social Work Commons

Let us know how access to this document benefits you.

\section{Recommended Citation}

Sandeen, Peggy Jo Ann, "Public Opinion and the Oregon Death with Dignity Act" (2013). Dissertations and Theses. Paper 1015.

https://doi.org/10.15760/etd.1015

This Dissertation is brought to you for free and open access. It has been accepted for inclusion in Dissertations and Theses by an authorized administrator of PDXScholar. Please contact us if we can make this document more accessible: pdxscholar@pdx.edu. 
Public Opinion and the Oregon Death with Dignity Act

by

Peggy Jo A Sandeen

A dissertation submitted in partial fulfillment of the requirements for the degree of

Doctor of Philosophy

in

Social Work and Social Research

Dissertation Committee:

Laurie Powers, Chair

Matthew J. Carlson

William Donlan

Jim Nash

Laura Nissen

Carol Pratt

Portland State University

2013 
(C) 2013 Peggy Jo A Sandeen 


\begin{abstract}
Oregon voters legalized physician-assisted death in 1997 by passing the Oregon Death with Dignity Act. This law allowed terminally ill, mentally competent adult residents of the state to legally obtain a physician's prescription to hasten death under narrow sets of circumstances. The purpose of this study was twofold: to examine contemporary patterns of support for the law in Oregon and to explore how opinions have changed over time on the issue. This study examined patterns of public support among a random sample of registered Oregon voters for the state's death with dignity law, using a mixed mode (mail, online, and phone) cross-sectional survey $(\mathrm{n}=442)$. The findings indicate a pattern of growing support with potential Oregon voters split $80 \%-20 \%$ on the issue, a substantial increase from the 60\%-40\% approval margin at the ballot box in 1997. Various demographic variables, as well as attitudinal factors, were explored in building a binary logistic regression model predicting probability of support. Frequency of church attendance, views about physician participation in the process, and opinions about Death with Dignity as an individual right were significant predictors of support. Frequent churchgoers, regardless of denomination or religious tradition, were nearly five times more likely to oppose Death with Dignity than support it, holding all other variables constant. While the findings indicate a pattern of growth in support over the past 15 years, they indicate also a stability of opinion, with few individuals indicating they had changed their opinions about the issue since the first time they encountered it.
\end{abstract}




\section{Table of Contents}

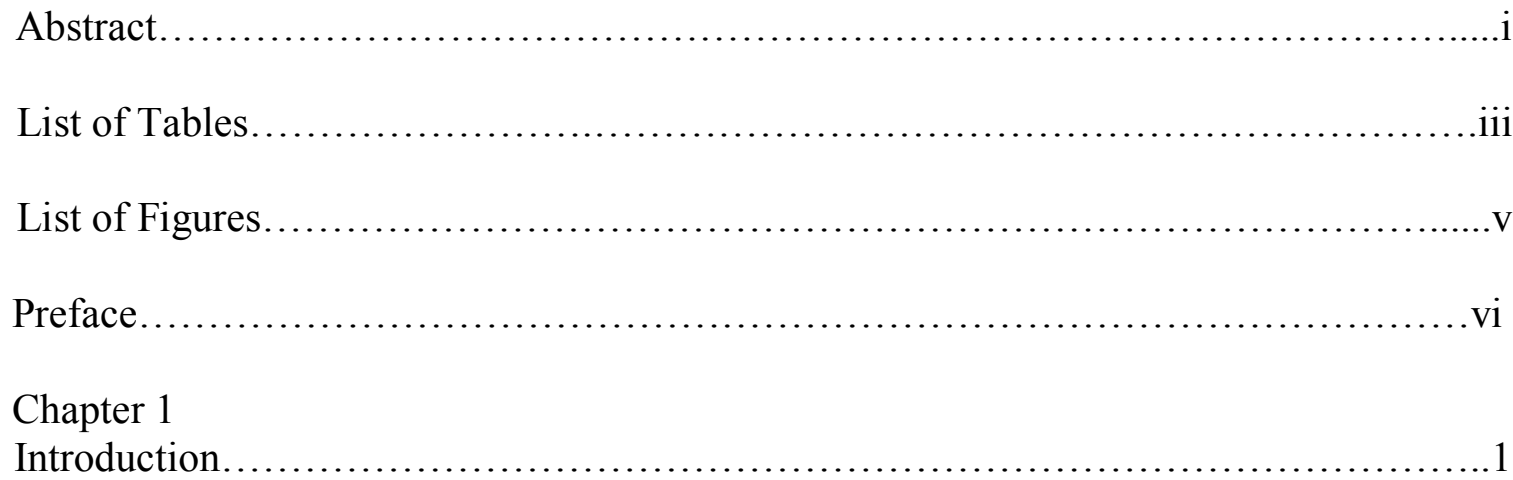

Chapter 2

Literature Review.........................................................9

Chapter 3

Methods...................................................................42

Chapter 4

Results...................................................................6

Chapter 5

Conclusions.............................................................93

References............................................................ 108

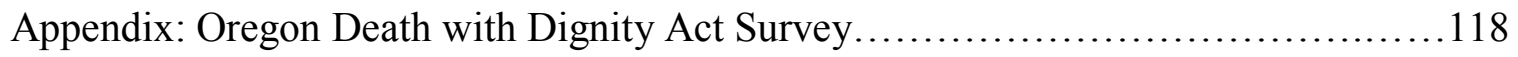




\section{List of Tables}

Table 1

Frequency distributions describing demographic variables and support for death with

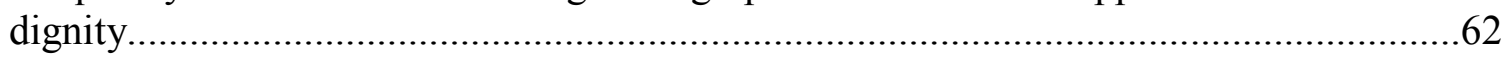

Table 2

Frequency distributions describing religion and support for death with dignity..........64

Table 3

Frequency distributions describing political affiliation and support for death

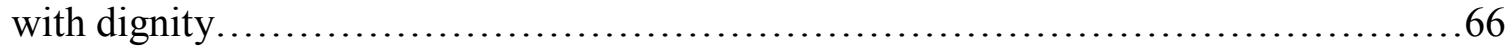

Table 4

Means and Standard Deviations for Perception Variables..........................70

Table 5

Means and Standard Deviations for Attitudinal Variables.

Table 6

Support for Death with Dignity in Oregon between 1994 and $2012 \ldots \ldots \ldots \ldots \ldots \ldots \ldots . \ldots 77$

Table 7

Magnitude and Direction Change for 36 Respondents Indicating an Opinion Shift

Over Time.

Table 8

Logistic Regression Predicting Opposition Using Religiously Oriented Variables

Table 9

Correlation Matrix for Model Co-Variates, Pearson's Correlation Values Reported.......84

Table 10

Logistic Regression Predicting Opposition Using Attitudinal Variables

Table 11

Logistic Regression Predicting Opposition Using Demographic Variables....

Table 12

Model-Predicted Probabilities. 


\section{List of Tables (continued)}

Table 13

Logistic Regression Predicting Opposition Using Demographic and Attitudinal Variables.............................................................. 91 


\section{List of Figures}

Figure 1

The stages of Issue Evolution Theory as applied to developments in the Death with

Dignity Movement.......................................................29 


\section{Preface: \\ Public Opinion and the Oregon Death with Dignity Act}

Advances in medical technology in the last 50 years have altered the dying process for individuals in the United States (Webb, 1999). No longer do Americans die at home, relatively painlessly and quickly, with their family members at their side. Antibiotics and other medications are available to treat conditions that formerly led to death in those with weakened immune systems or those who are terminally ill (e.g. pneumonia). Physicians today have unprecedented skills, training, and technology to prolong life beyond any point conceivable a generation ago. While these advances in technology are overwhelmingly viewed as positive, the concomitant changes in the trajectory of the dying process can bring much suffering to some individuals who are dying. A small percentage of individuals who experience a protracted dying process, largely brought about by the extension of their lives through medical intervention, may not find relief in modern medicine (Preston, 2006; Quill, 2012). There are few legal options to hasten death, and for most of the past 15 years, Oregon was the only state where individuals could lawfully look to their personal physicians for assistance.

When Oregon adopted the Death with Dignity Act (DWDA) in 1994 by citizen's initiative, the law was largely viewed as an experiment. Today, the law is considered model legislation to be replicated in other states (Stutsman, 2004). This study examined public opinion and the changes in public opinion about the Oregon Death with Dignity Act from 1993 to 2012. The study set out to explain patterns of support for DWDA, 
overall and among specified demographic groups, while at the same time describing how and why support changed over time. This study aimed to contribute information about death with dignity to the body of knowledge concerning opinion dynamics - the specialized field exploring how and why public opinion changes in the aggregate over time.

This document contains an overview of the study and its findings from hypothesis to conclusions. Chapter One provides a summary of the Oregon Death with Dignity Act and usage patterns over the 15 years since implementation; Chapter Two is a literature review presenting theoretical support for the study's hypotheses and information about the variables; Chapter Three provides a review of the methods used during the study; Chapter Four features the results; and Chapter Five is a discussion of the results, including limitations, implications for policy and practice, and recommendations for future research. The Appendix contains a copy of the survey instrument. 


\section{Chapter 1 \\ Introduction}

The Oregon Death with Dignity Act governs the practice of medicine with terminally ill individuals who request prescriptions to hasten their deaths. Death with Dignity is a law supported by a majority of Americans (Harris Interactive, 2005; Gallup, 2007), but available only to residents of Oregon and, as of March 5, 2009, Washington (Steinbrook, 2008). DWDA stipulates that an adult resident of Oregon must be deemed terminally ill and mentally competent by two different physicians in order to receive a prescription to hasten death. The qualified individual must be physically able to ingest the medication without assistance, and he or she may choose to not take the prescription at any time. Nearly $40 \%$ of individuals who received the prescription in the last 15 years did not take the medication (Oregon Health Authority, 2013).

The law remains controversial particularly among faith-based opponents who believe that the act of prescribing a life-ending medication is tantamount to murder and an affront to a Christian God. (John Paul II, 1995) Other opponents include advocacy groups supporting people with disabilities and the American Medical Association (AMA). Both groups believe that the Act is dangerous for vulnerable individuals (those with disabilities, individuals who are impoverished, and people of color) and that physicians who prescribe medication under the DWDA are acting unethically (Coleman, 2002). These opponents to the law have played a substantial role in preventing Death with Dignity legislation from passing in other states, but they are largely silent in Oregon (Stutsman, 2004). 
There is anecdotal evidence to suggest that more Oregonians support the law today than did so in 1994 when it was passed, but only one published study has examined public opinion in Oregon since the law's passage (National Journal, n.d.). According to this 2011 poll, $78 \%$ of respondents supported death with dignity, while $20 \%$ opposed it. Evidence suggests the state's elected officials overwhelming support Death with Dignity. According to Stutsman (2004), all six of the Oregon gubernatorial candidates pledged support for the law in the 2002 primary. During the same year in a proprietary survey of Oregonians conducted for the Oregon Death with Dignity Political Action Fund, Stutsman reported that $45 \%$ of Oregonians cited Senator Gordon Smith's efforts to overturn DWDA as "a very convincing reason" to vote him out of office. Data from this same survey indicate that $41 \%$ of Oregonians believed that the Senator's opinion on Roe v. Wade was "a very convincing reason" to vote him out of office (Stutsman). Fewer voters would vote him out because of his opinions on lesbian and gay issues and gun control. Stutsman interprets this data as an indication that, for Oregonians, the Death with Dignity Act is a stronger candidate litmus test than abortion, opinions about rights for lesbians and gays, and gun control. According to Stutsman, to be viable candidates for statewide office, would-be office-holders must assert their public support for the DWDA. This survey provides apparent, albeit indirect, evidence of widespread public support for DWDA in Oregon.

Conversely, there is strong and indirect evidence to suggest that the public controversy has not ended in Oregon. In 2008, a Death with Dignity initiative was placed 
on the ballot in Washington State. During March of that year, The Sunday Oregonian ran an editorial lauding the Death with Dignity Act for its role in advancing access to palliative care, treatment of pain, and hospice use. Editors at The Sunday Oregonian concluded, "Opponents, including us, warned that the law could steamroller vulnerable patients into suicide, target the disabled and become a destination for terminally ill people seeking to die with doctor-prescribed drugs. In a decade of experience with the law, though, no such abuses have shown up.” (Booth Gardner, 2008, p. E4). Eight months later, however, The Oregonian refused to endorse the Washington initiative, saying that physicians and pharmacists should not intentionally hasten death (Aid in Dying, 2008, p. E4). This seeming contradiction is illustrative of the national inconsistency demonstrated on the issues; there are high levels of public support with concomitant lack of support for policy change.

\section{The History of the Oregon Death with Dignity Act}

On November 1, 1994, Oregon voters approved the Oregon Death with Dignity Act, a ballot initiative allowing individuals with a terminal illness to request and receive a prescription to voluntarily hasten death when specific safeguards have been met. In doing so, the state of Oregon established standards, oversight, and guidelines for the medical practice of physician-assisted dying.

Oregon was the first state to establish any sort of law addressing physicianassisted dying, following ballot initiative losses in both Washington (1991) and California (1992). Voters in Washington and California considered policy proposals that 
were more expansive than the current Oregon law, policies allowing a physician to inject a lethal dose of medication. Oregon law prohibits the practice of lethal injections, mandating the patient be physically able to ingest the medication.

In the nearly 20 years since passage, the law has been assailed repeatedly by opponents including efforts in the Oregon state legislature, the federal court system, and Congress. Immediately following passage of DWDA, U.S. District Court Judge Hogan issued a restraining order preventing implementation of the law. The restraining order was lifted on October 27, 1997, by the Ninth Circuit Court of Appeals, and the law was immediately implemented (Oregon Health Authority [OHA], 2013c). Three years after voters approved the law, terminally ill adult residents of Oregon were provided the option of requesting and receiving a prescription from their physician to hasten death.

In 1997, both houses of the Oregon legislature voted to return the death with dignity ballot initiative back to the people for repeal. The special repeal election was held November 4, 1997; the first attempt to overturn the will of the electorate since 1908 (OHA, 2013c). The final vote was $60 \%-40 \%$ against the repeal effort. Oregon's law remained in effect.

This particular set of state-based challenges was not the final endeavor to overturn Oregon's law. In two consecutive years, Congress attempted to ban the process of physician-assisted dying, first with The Lethal Drug Abuse and Prevention Act of 1998 and then with The Pain Relief Promotion Act of 1999. Both efforts were unsuccessful. On November 6, 2001, Attorney General John Ashcroft issued an interpretation of the 
Federal Controlled Substances Act which would have allowed federal drug agents to punish physicians and pharmacists who prescribed medications under Oregon's Death with Dignity law (OHA, 2013c).

On November 20, 2001, a temporary restraining order against the Ashcroft ruling was put into place by the U.S. District Court. This case wound its way through the federal court system over the following six years, with the U.S. Supreme Court deciding against Ashcroft's ruling on January 17, 2006 (OHA, 2013c). There are currently no challenges pending against the Oregon Death with Dignity Act, and the law has been continuously implemented since October, 1997.

\section{The Contents of the Law}

Oregon's Death with Dignity Act is a prescribing-only law, meaning the procedures for physicians and pharmacists are spelled out in the law and that euthanasia, lethal injections, and mercy killing are not allowed. The law is a codified medical standard of care for physicians and pharmacists to follow when a qualified terminally ill patient requests physician assistance with hastening death. DWDA identifies the process for how a terminally ill individual becomes qualified, procedures for physicians to follow in prescribing, charting, and reporting, and steps for the state to follow in issuing an annual report to the general public.

Arguably, the most important section of the Act is Section 3 entitled "Safeguards," and it spells out the provisions of the law that provide protection against coercion. This section identifies 12 steps for attending physicians to follow, including 
procedures for ensuring informed consent, provisions for rescinding the request, and referrals to counseling. In addition, it mandates a referring physician to concur with the attending physician in regard to confirming a diagnosis of terminal illness, assessing for mental competency, and ensuring the patient is acting voluntarily. Other safeguards focus on the individual with a terminal illness, mandating waiting periods, written and oral requests for a prescription, and counseling referrals for determining if individuals are mentally competent to make the decision if either physician has a question about a person's competence.

The steps for qualifying are spelled out in the law: an individual must be diagnosed with a terminal illness leading to death in six months, be determined mentally competent and acting voluntarily through an informed decision, and be an adult resident of Oregon. Two physicians must agree these conditions exist. Once the person qualifies, he or she must submit an oral request for a prescription, wait 15 days, submit another oral and written request, and pass another 48 hour waiting period before receiving a prescription. The suggested written request form is codified within the law, outlining provisions that must be included in the request and providing guidance as to the relationship of witnesses to the terminally ill individual. Ultimately, the qualified person must be able to self-administer the medication voluntarily with no assistance from family, friends or healthcare professionals. 


\section{Use of the Law in Oregon}

In the 14 years since the law was first implemented, 1,050 individuals have received prescriptions under the Death with Dignity law, and 673 individuals have followed the requirements of the law to hasten their deaths (OHA, 2013a). Of the 673, a majority of individuals, $51.6 \%(n=347)$ were male, with $48.4 \%(n=326)$ females. The median age of individuals who ingested the medication was 71 (range 25-96), and most participants were white $(97.6 \%, n=654)$. The racial breakdown for individuals of color who participated was as follows: $1.2 \%$ Asian $(n=8) ; 0.1 \%$ American Indian $(n=1)$; $0.7 \%$ Hispanic $(n=5)$. A total of $45.4 \%$ of participants were married, and the remaining were widowed (23.4\%), divorced (23.0\%) or never married (8.2\%).

Most of the individuals who used the law in the last 14 years were identified as having some form of cancer as the underlying terminal disease $(n=538,80.3 \%)$. Amyotrophic lateral sclerosis (ALS), also known as Lou Gehrig's disease, was the second most common terminal diagnosis among participants, with 39 individuals (7.3\%) diagnosed with ALS. The rest of the participants suffered from various other terminal diseases including HIV/AIDS, heart disease, chronic respiratory disease, and scleroderma (OHA, 2013a).

In the early years of implementation, few individuals requested and/or ingested the life-ending medication. Over the years, usage increased. During the most recent four years of implementation (2009-2012), for example, there have been 59, 65, 71, and 75 deaths, respectively, and 95, 97, 114, and 115 prescriptions written (OHA, 2013a). There 
are occasional spikes, as a dramatic increase in the number of prescriptions written between 2006 and 2008 illustrates, but for the most part the trend is a gradual upward slope. This pattern is found in the number of physicians writing prescriptions, which increased from 22 in 2000 to 61 in 2012, spiking at 64 in 2009 (OHA, 2013b). Data on this variable was not collected during the first two years of implementation. 


\section{Chapter 2 Literature Review}

This literature review contains four main sections - a discussion of the importance of this issue to social work, a review of historic and contemporary public opinion polls, a conceptual framework, and an overview of variables to be used in this study. In the first section of the literature review, the relevance of this topic to social work is discussed. In the second section, a discussion is undertaken to explain how public opinion is an essential skill for social work policy-practitioners. The third section uses the work of polling theorist, James Stimson, to provide a conceptual framework for this proposal. The final section examines the major predictor variables (political affiliation, age, education and income, and religiosity) and outcome variable (support) used in this study. This chapter concludes with research questions used in the study.

\section{Importance for Social Work}

While dissertations about public opinion may be common in political science, they are rare in social work. The study of public opinion and polling, on the surface, seems far afield from social work. Wyers (1991) offers a starting point for describing the importance of specialized skill sets (expertise in interpreting public opinion data, for example) to social workers who are policy-practitioners. He identifies five models of social work policy practice: social worker as policy expert, social worker as change agent in external work environment, social worker as change agent in internal work environment, social worker as policy conduit, and social worker as policy itself. The model for this dissertation proposal is "social worker as policy expert," which explains 
how social workers can be policy experts with a specific set of macro-level skills, different from the skills needed to practice directly with clients (Wyers).

Wyers (1991) describes the main function of policy-practitioners as molding, shaping or analyzing policies so that the best possible services are available to individuals who need them. In this model, policy-practitioners do not work to improve the lives of individual clients or family members per se, but rather work to change policies impacting large numbers of individuals. Because of the difference in scope, macro-level interventions as opposed to the more common micro-level interventions, policypractitioners must develop a different skill set. The development of specialized research skills necessary to design, conduct, and analyze polling is crucial for policy-practitioners.

While this project reflected a specific skill that is critical for social work policypractitioners, an examination of the National Association of Social Workers (NASW) Code of Ethics is a helpful place in beginning to understand the importance of enacting Death with Dignity laws in other states. Section 6.04 of the Code provides a mandate for social workers to be involved in political action, stating, "Social workers ... should advocate for changes in policy and legislation to improve social conditions in order to meet basic human needs and promote social justice," (NASW, 2008, n.p.).

Furthermore, in states without Death with Dignity legislation, Quill \& Cassel (2004) note that the medical practice of hastening death occurs in a "don't ask, don't tell" fashion, without open discussion between physicians and patients, without documentation and without consultation. Quill and Cassel illustrate that physicians may agree to help 
their patients hasten death without fully disclosing the details of the process or seeking consultation with other physicians for fear of prosecution. Such practice, in a secretive environment without complete informed consent, is not consistent with social work values. The "don't ask, don't tell" process does not promote the values set out in the preamble of the Code: autonomy, self-determination and the inherent dignity and worth of the person. If Quill and Cassel (2004) are correct in their assertions, the current process does not comply with NASW Code of Ethics standards for informed consent. This area of medical social work practice is ripe for political involvement by social workers, as suggested by the NASW Code of Ethics. Arguably, the current process of physician-hastened death in states without DWDA is inconsistent with social work values, and social workers may interpret the Code as establishing an ethical mandate to advocate for policy and legislative change.

The findings of this study are important to social work, in terms of both policy practice and direct practice. For policy-practitioners, the findings may be helpful in achieving success in enacting Death with Dignity laws through the direct initiative process. Policy-practitioners who work in other areas may use the methods, analysis or findings in their study of other policy arenas. Policy-practitioners who explore largescale changes in public opinion may use these particular data to understand how the American public vacillates between support and opposition on other issues relevant to social work, including the provision of social welfare services or non-discrimination laws. 
Direct practitioners may benefit if the findings of the proposed study are used to enact Death with Dignity laws in states other than Oregon. Currently, in all states other than Oregon and Washington, if a terminally ill patient requests assistance in hastening death, a social worker has few options. Such requests may not be rare, according to Tolle, Tilden, Drach, Fromme, Perrin, \& Hedberg (2004). In a study of Oregonians, these researchers found that $17 \%$ of terminally ill Oregonians considered physicianhastened death and $2 \%$ formally requested it. The study sample was the family members of 2,197 adult Oregonians who died of natural causes (not accidents or sudden deaths) between June 2000 and March 2002. Similarly, in a study of 832 social workers in the state of Washington, Ogden and Young (2003) found 20\% of participants had been consulted about voluntary euthanasia or assisted suicide by their clients, friends, or associates.

When a terminally ill individual seeks assistance regarding physician-hastened death, the social worker may refer the patient to a physician who is willing to participate in the "don't ask, don't tell" process, but, as noted above, that process may be rife with potential violations of ethical practice in social work. If unwilling to participate in the "don't ask, don't tell" scenario, the social worker, when asked for assistance with hastening death, may refuse to participate or offer the alternative solution of voluntary dehydration and terminal sedation. With limited options, social work direct practitioners working in end-of-life care need death with dignity laws so that they may legally respond to requests for assistance from their clients, if they so choose. 
In order to advocate for Oregon-style Death with Dignity legislation which contains standards for informed consent and promotes self-determination and autonomy, social workers must first understand public opinion about the issue. While dissertations about public opinion may be common in political science, they are rare in social work. In this case, however, understanding public opinion is a critical step in understanding how Death with Dignity laws in states other than Oregon can be enacted.

Overall, this study is an important piece of social work research in Oregon. It addresses issues of autonomy and self-determination, core principles outlined in the NASW Code of Ethics (2008). It provides insight into on particular healthcare policy that has been law in the state of Oregon for 15 years, and it acts as a research model for social workers participating in empowerment research or other types of research challenging the dominant discourse on issues related to social justice.

\section{Public Opinion and Policy Outcomes}

Lack of success in legislatures and the initiative process. The U.S. Supreme Court determined in Glucksberg v. Washington (1996) that the act of physician-assisted suicide is not protected under the United States Constitution, concluding, rather that it is an issue properly left to the states to regulate. The justices were unified in their decision, voting 9-0 on the matter. Justice O'Connor, in her concurring opinion noted, "As the Court recognizes, States are presently undertaking extensive and serious evaluation of physician-assisted suicide and other related issues...In such circumstances, 'the...challenging task of crafting appropriate procedures for safeguarding...liberty 
interests is entrusted to the 'laboratory' of the States."' (Glucksberg v. Washington, p. 737). In the absence of federal guidance, states are free to enact their own laws governing the practice of Death with Dignity.

Repeatedly, though, state legislatures have failed to act on proposed Death with Dignity legislation. In 2002, the Hawaii legislative assembly came closer to enacting an Oregon style law than any other state has come. Stutsman (2004) notes that the proposed Hawaii law was sponsored by the state's governor and was successfully shepherded through the committee process by supporters. The process continued favorably with a 30-20 vote in the House; however, the law was stymied by the Senate, with a 14-11 floor vote against passage, following extensive lobbying from religious opponents (Stutsman).

Since then, significant legislative efforts have been made in Vermont during four different legislative biennia $(2006,2008,2010$, and 2012), with the efforts lacking the political momentum to achieve a winning vote in both houses of the legislature. In California in 2007, an Oregon-style Death with Dignity law was introduced with much fanfare, boasting the Assembly Speaker as one of the bill's sponsors. Assembly Bill 374 lingered in the Judiciary Committee of the Assembly, failing to be voted out of committee in time to meet a crucial deadline.

Similar legislation has been introduced repeatedly in Arizona and Iowa, with no action by legislators. In 2012, there were bills pending in the Hawaii, Montana, Connecticut, New Jersey, New Hampshire, Massachusetts, and Vermont legislatures with Vermont being the only state likely to experience significant legislative action. 
In the absence of success in the legislative arena, advocates of death with dignity have achieved success using the citizen's initiative process, whereby individual citizens engage in an extensive signature gathering process and bring proposed laws to the ballot. Citizens who live in states with the direct initiative process can enact laws without legislative involvement. Oregon's death with dignity law was enacted in this fashion in 1994, and Washington's law succeeded as a citizen's initiative in 2008. Maine was nearly a success in 2000 , failing in a statewide vote $51-49 \%$ (Stutsman, 2004). Given that enactment of the law has succeeded only through the initiative process which is dependent on public opinion for campaign message testing, political strategy development, and campaign monitoring, understanding factors that impact public opinion is crucial.

Public opinion in states with direct initiatives. One researcher (Arceneaux, 2002) demonstrated that states with the direct initiative process had laws that were more responsive to public opinion than states without it, using the controversial public policy area of abortion. Arceneaux analyzed data from the General Social Survey (GSS) disaggregated by state to illustrate that states with more progressive general attitudes toward abortion and the direct initiative process had more progressive laws than states without the direct initiative process; and conversely, states with more conservative general attitudes toward abortion and the direct initiative process had more conservative public policies than states without the initiative process. Arceneaux cautions against 
generalization, but Death with Dignity may be a policy area where his findings are applicable.

Lascher, Hagen, \& Rochlin (1996) found contradictory evidence-their study examined data from nine policy areas. The authors concluded that the existence of the initiative process does not result in laws that are more congruent with public opinion. They, too, provide cautions about generalization, illustrating that initiative states with public opinion supporting legislative term limits are more likely to have term limit legislation than states without the initiative process. Certainly, there is no strong evidence suggesting that a state such as Oregon is more likely to have policy that is more in line with public opinion about death with dignity simply because the initiative process exists in the state.

There is no direct evidence illustrating that social work policy-practitioners who are working toward enactment of DWDA laws in states other than Oregon must understand public opinion. However, there is a collection of strong anecdotal evidence suggesting policy-practitioners must understand factors that impact public opinion. One researcher found that states with the initiative process had laws which were more consistent with public opinions (Arceneaux, 2002); another set of researchers (Lascher, Hagen, \& Rochlin, 1996) came to the opposite conclusion with strong reservations about generalizing to other issues beyond the scope of the research. Death with dignity has been attempted by multiple state legislatures, but has never been successful. However, it has succeeded in three different ballot initiatives (twice in Oregon and once in 
Washington). Those ballot measures made extensive use of public opinion polling. If the pattern persists, and state legislatures continue to strike down death with dignity laws while ballot measures are successful, social work policy-practitioners must understand public opinion to be successful with ballot measures.

Public opinion and policy outcomes. While a logical chain of events would suggest that public opinion matters in terms of death with dignity policy-making, some researchers and theorists disagree in their ideas about the impact of public opinion on policy outcomes. Stimson, MacKuen, and Erickson (1995) assert that public officials are responsive to the general public, while Zaller (1992) and Arnold (1990) argue that contemporary issues are so complex that the public cannot understand whether or not their interests are reflected through the process of government.

Page and Shapiro (1983) examined 357 occasions when American public opinion on domestic or foreign policy issues changed from 1935 to 1979. They found a great deal of congruence between opinion change and policy change, stating, "We think that it is reasonable in most of these cases to infer that opinion change was a cause of policy change, or at least a proximate or intervening factor leading to government action, if not the ultimate cause," (Page \& Shapiro, p. 186). The authors, however, offer the caveat that there are specific policies in which change was non-congruent with public opinion; the state of living in a democracy does not always ensure policies will reflect the will of the public. 
Most recently, Burstein (2003) reviewed 30 studies examining the effect of public opinion on policy outcomes. Burstein found a statistically significant relationship between public opinion and policy outcomes in nearly $75 \%$ of the studies. Of the studies that explored the magnitude of the relationship between public opinion and policy outcomes, nearly all evaluated the impact as "substantial." Burstein concluded, “...so far as we can tell from published research, policy is affected by opinion most of the time; often — over half the time when public opinion has any effect — the impact really matters substantially," (Burstein, p. 34). Taken together, the research of Burstein and Page and Shapiro (1983) suggests that significant changes in public opinion regarding death with dignity will lead to changes in policy. Understanding the factors that contribute to favorable public opinion, in turn, may help advocates develop political strategies which will lead to success in other direct initiative states.

\section{Public Opinion Regarding Death with Dignity}

National polls. Americans support the idea of Death with Dignity, and consistent polling by both the Gallup Organization and the Harris Poll demonstrate that in a typical year, 6 of 10 Americans support Oregon-style laws. Language is critical in polling, and when the word "suicide" is used, support declines; without the word "suicide" support increases. In order to gauge support for an Oregon-style law, it is important to restrict examination of polling questions to ones which reference the Oregon law or speak to the question of a physician assisting a mentally competent and terminally ill patient to hasten 
his or her death. Questions about other issues, such as euthanasia, will not be explored here.

The Gallup Poll has surveyed Americans on the issue repeatedly since 1947, asking the question, "When a person has a disease that cannot be cured, do you think doctors should be allowed by law to end the patient's life by some painless means if the patient and his family request it?” (Carroll, 2006, n.p.). In 1947 and 1950, support for this question was low with $37 \%$ and $36 \%$ of Americans responding "yes" respectively. Support for the issue as conceptualized in this one polling question gradually increased between 1973 and 1996, peaking at 75\% in 1996. In the 10 years since 1996, the Gallup Poll has asked the same question 7 times, with support ranging from $65 \%$ to $75 \%$.

When the question is changed to include the word "suicide," the pattern of positive responses looks markedly similar, but the percentage of positive responses is lower. If the responses were placed together on a graph, the lines would be roughly parallel with the responses using the word suicide one or two percentage points lower across the graph. The Gallup Poll asked the following question 11 times between 1996 and 2006, "When a person has a disease that cannot be cured and is living in severe pain, do you think doctors should or should not be allowed by law to assist the patient to commit suicide if the patient requests it?" (Carroll, 2006, n.p.). Between 52\% and 68\% of those questioned responded affirmatively to this question, with an upwards trend from 1996 to 2001, and a fluctuating, but continued majority support between 2001 and 2006 . 
The Harris Poll has surveyed Americans about this topic six times since 1982. This polling company asked respondents, "Do you think that the law should allow doctors to comply with the wishes of a dying patient in severe distress who asks to have his or her life ended, or not?” (The Harris Poll, 2005, n.p.). Support for this question increased from 53\% in 1982 to $73 \%$ in 1993 ; most recently, $70 \%$ of those surveyed responded yes in 2005 .

The Harris Poll has twice asked specifically about Oregon's law, querying respondents about the following question:

There is an Oregon law which allows doctor-assisted suicides for PATIENTS WITH LESS THAN SIX MONTHS TO LIVE. Doctors are allowed to help these patients end their lives - but only if - all of the three following conditions are met: 1) The patient requests it three times; 2) There is a second opinion from another doctor; and 3) There is a 15-day waiting period for the patient to change his or her mind. Would you favor or oppose such a law in your state? (Harris Poll, 2005, n.p.)

In $2001,61 \%$ of respondents favored the proposed law, while $34 \%$ opposed it $(n=$ 1,011). The remaining respondents $(5 \%)$ were not sure or refused to answer. By 2005 , support had risen nationally with $67 \%$ responding in favor of the law, and $32 \%$ against it $(n=1,010)$. Only $1 \%$ of the respondents indicated that they were not sure or refused to answer the question. There was a $+/-3 \%$ margin of error reported for both polls. 
Public opinion in Oregon. Oregonians demonstrate similar patterns of support for their own death with dignity law; however, most of the available data are more than 15 years old. In a proprietary unpublished poll conducted for Oregon Right to Die (the Political Action Committee responsible for the 1994 death with dignity proponent campaign in Oregon), 700 Oregonians were asked the following question, "Shall the law allow terminally ill adult patients the voluntarily informed choice to obtain a physician's prescription for drugs to end life?" (Fairbank, Maslin, Maullin, and Associates, 1994, p. 1) approximately two months before the election was held. A total of $43 \%$ of respondents indicated that they would definitely vote yes and $16 \%$ indicated they would probably vote yes on the ballot measure. Twenty-one percent said that they would definitely vote no, whereas $10 \%$ indicated they would probably cast a no vote for this measure. Two months before the election, 11\% did not know how they would vote. Ultimately, the Oregon law was passed by the voters by a $51 \%-49 \%$ margin on November 1, 1994 (Stutsman, 2004).

In 1997, the Oregon legislature sent the Act back to the voters for reconsideration. Ganzini (2004) suggests that members of the legislature were not convinced that Oregonians had been sufficiently thoughtful in casting their ballots in 1994. At that time, Oregon Right to Die commissioned another proprietary public opinion poll of Oregonians prior to this legislative referendum which would have overturned the Oregon Death with Dignity Act. 
GLS Research conducted a telephone survey of 600 randomly selected Oregonian voters between February 20 and February 23, 1997, and the following information is extracted from the unpublished pollster's memo. The survey contained the same question put to the voters in the 1994 survey, "Shall the law allow terminally ill adult patients the voluntarily informed choice to obtain a physician's prescription for drugs to end life?" (Paul Goodwin, personal communication, February 28, 1997, p. 3). Support for the Oregon law increased over the years, with $49 \%$ of respondents indicating that they definitely vote for the law and $12 \%$ indicating they probably would vote yes. There were a higher number of "definitely no" votes than the 1994 survey, with $27 \%$ indicating that they would definitely vote against the measure in 1997, an increase of 6\% from 1994. Only $6 \%$ of individuals indicated that they would probably vote against the law, while $5 \%$ remained undecided. Goodwin reported the margin of error for this poll was $+/$ - four percent at the 95 percent confidence level.

After the 1997 election where the voters rejected the repeal referendum $40 \%-60 \%$ (Ganzini, 2004), Oregon Right to Die commissioned a final proprietary poll of Oregon voters. According to an unpublished memo from the pollster Paul Goodwin (personal communication, February 9, 1998), 600 voters were randomly selected to participate in the telephone survey. The margin of error was $+/$ - four percent at a 95 percent confidence level. Results from this poll indicate support for the law increased in the year since the last poll, with $54 \%$ of respondents indicating they definitely would vote for the measure, while $11 \%$ said that they probably would. Twenty-seven percent said that they 
definitely would not vote for the measure, while $5 \%$ would probably not vote for the measure. Only $3 \%$ remained unsure as to how they would vote. The pollster concluded from these results that “...we have seen attitudes towards Measure 16 become more polarized, with the 'definitely' yes and no camps growing and the fraction who would 'probably' vote yes or no, and the fraction who are undecided, shrinking over time. After four years of debate, most voters in Oregon have made up their minds." (P. Goodwin, personal communication, February 9, 1998, p. 4).

It is important to consider context when evaluating these polling numbers. All of the surveys were conducted within months of very contentious public debate on the issue. There was extensive newspaper media coverage, and the state's main newspaper editorialized against the proposed law repeatedly. The proponents and the opponents both ran frequent advertising on television and radio. It is safe to assume the public debate had an impact on voters' opinions, and several researchers (Burstein \& Linton, 2002; Kingdon, 2003; Fording, 1997; Amenta \& Poulsen, 1996) have demonstrated that social movement organizations and interest groups affect policy to a certain degree. The unknown factors are the magnitude and direction of the impact. With social movement organizations and interest groups on both side of the issue engaged in a heated public debate and an absence of data from Oregon when there was not ongoing polarized dissension, it is impossible to determine the impact of the campaign on public opinion. While the proponents prevailed at the ballot box twice, it is unclear how public opinion 
would have moved or stayed the same on the issue of death with dignity absent the campaign tactics from proponents and opponents.

\section{Conceptual Framework}

Stimson's seminal work (2004) explains how public opinion moves over time and how public opinion shapes public policy. His ideas are useful in providing a model describing how public opinion about death with dignity may have changed over time in Oregon. Stimson notes that there is a paucity of theories explaining aggregate public opinion change over time. According to Stimson,

It is probably impossible to say what single thing is the most important factor in American politics, but I believe that thing is public opinion movement...And important though it is, we have only scratched the surface of understanding opinion movement. It is almost unknown in a systematic sense, in a sense of regular theories and analyses.

(p. xvi)

In attempting to address the gap in theoretical explanations, Stimson (2004) posits an Issue Evolution Theory which describes how issues arise, take shape, and capture the attention of Americans. This theory assumes that our society is large and complex, continually producing issues that create public controversy, but at the same time, boasting limited political capacity. Campaigns and elected officials can only address a small number of these issues. Stimson describes how certain novel issues gain rapid attention after a notable event thrusts a matter into public attention. He describes the monumental 
Roe v. Wade decision and Barry Goldwater's vote against the Civil Rights Act of 1964 as "critical moments" when signals were sent to the public that a new policy position was imminent.

After exploring how an issue gains prominence using the Issue Evolution Theory, Stimson (2004) explores the concept of issue alignment — whereby he asserts that issues become aligned with a particular political party. He argues that these alignments are not "naturally occurring," but rather that party positions on new issues are socially constructed by political elites whose opinions and positions are gradually adopted by the general population. During the early stages of issue alignment, the two political parties vacillate in their support for, or opposition to, an issue until one side or another takes a firm position. When this polarization occurs, peoples' opinions change over time to be in line with their party's position on issues; hence, the alignment of a particular position of an issue with a particular political party is socially constructed. In the advanced stages in the evolution of a new social issue, individuals use political party cues to determine support or opposition to an issue (Stimson).

Issue Evolution Theory. According to the Issue Evolution Theory (Stimson, 2004), during the time span following the "critical moment," voters are not aligned with a particular side of the issue, and neither are political parties. Drawing from the work of Converse (1964) who applied concepts from social learning theory to politics, Stimson argues that opposing sides of controversial issues are not naturally linked to the political parties from the beginning - rather an entrenched and dichotomized support/oppose 
stance by each of the political parties is socially constructed over time. Eventually, as an issue gains prominence, the political elites and party activists take a position, and the opposing party may take the opposite position to gain public support. Stimson describes this process in terms of social construction, stating:

The key idea here is that things 'seem' logically linked [Republican Party and tax cuts]. But if we use our deductive logic to demonstrate that link, in virtually every case we fail. Things that seem to go together do not in fact have logical connections. The phenomenon of seeming to go together...is more a matter of psychology (what symbols are shared) and social learning (what kinds of ideas are learned together in one's social background). The key thing... is that our idea of consistency is learned. It is something that is not objectively true, but rather socially constructed. We get used to the idea that certain positions are advocated together by the same people at the same times and places and come to believe that they are logically tied. (p. 68)

While the public tends to believe that the political positions of Republicans and Democrats are logically linked (Republicans support tax cuts, Democrats big government; Republicans are pro-life, Democrats pro-choice), Converse and Stimson illustrate how these ideas are socially constructed. Immediately following the Roe $v$. Wade decision, it appeared the Republican Party would become the pro-choice party because of the vocal support for abortion rights from a strong phalanx of Republicanidentified suburban educated women. History illustrates that the Democratic Party would 
eventually become the party advocating for pro-choice positions. Similarly, we assume that the Republican Party has always been interested in tax cuts, but it was not until President Reagan offered a series of tax cuts that the Republican Party became aligned with this policy position. Today, the common assumption is that tax cuts and the Republican Party have always been linked, but, in truth Stimson argues, the link was socially constructed in the 1980 s.

Stimson (2004) explains these seeming anomalous conditions through the Issue Evolution Theory. When a new issue bursts into the public mindset, the political parties do not align immediately with one side of the issue or the other. There is a period of time following the "critical moment" when individuals and parties are unaligned. Opposing sides are not taken and particular ideological positions are not entrenched the moment an issue appears. A period of time passes before a policy position and core political party beliefs seem to be logically and historically linked. The Issue Evolution Theory suggests that the seeming link is socially constructed, as leaders from each political party slowly adopt a position on an issue (and a rationale for that position).

In order to demonstrate that an issue is evolving along the trajectory suggested by the Issue Evolution Theory, Stimson (2004) concludes that three factors must be present: a "critical moment," a politically-unaligned electorate associated with the time period prior to the moment, and an increase in party polarization over the issue following the "critical moment." The evolution of the Death with Dignity policy roughly follows Stimson's suggested pattern. The critical moment may be traced to 1990 when several 
momentous events catapulted the issue into the mainstream media. Jack Kevorkian assisted in the death of Janet Atkins in the back of a van in Oregon under the watchful eye of the American public (Law, 2004). Derek Humphy, the founder of the Hemlock Society, published a suicide manual, Final Exit, which rose to the top of the New York Times best seller list within months (Law). In that same year, Congress passed the Patient Self-Determination Act which requires hospitals to inform patients of their rights to refuse end-of-life care and to sign an advance directive (Law). The U.S. Supreme Court ruled on its first right-to-die case, Cruzan v. Missouri Department of Health (1990), determining the United States Constitution grants a competent person the right to refuse lifesaving hydration and nutrition. And, finally, in the field of medicine, Dr. Timothy Quill assisted in the death of a patient "Diane" and published an account of the experience in The New England Journal of Medicine (Quill, 1991). With five different events in one year, including a Supreme Court decision and Congressional action, Stimson's criterion of a defining critical event is met. Figure 1 illustrates Stimson's Issue Evolution Theory and applies the timeline of the death with dignity movement to the theory.

A proprietary poll conducted on behalf of Citizens for Patient Self-Determination (an organization supporting I-119, a Washington State Death with Dignity ballot initiative allowing lethal injections) found that early in the campaign, the initiative enjoyed support from a majority of both Republicans (57\%) and Democrats (72\%). As the campaign entered its public phase, running television advertising and engaging print 
Figure 1. The stages of Issue Evolution Theory as applied to developments in the Death with Dignity movement

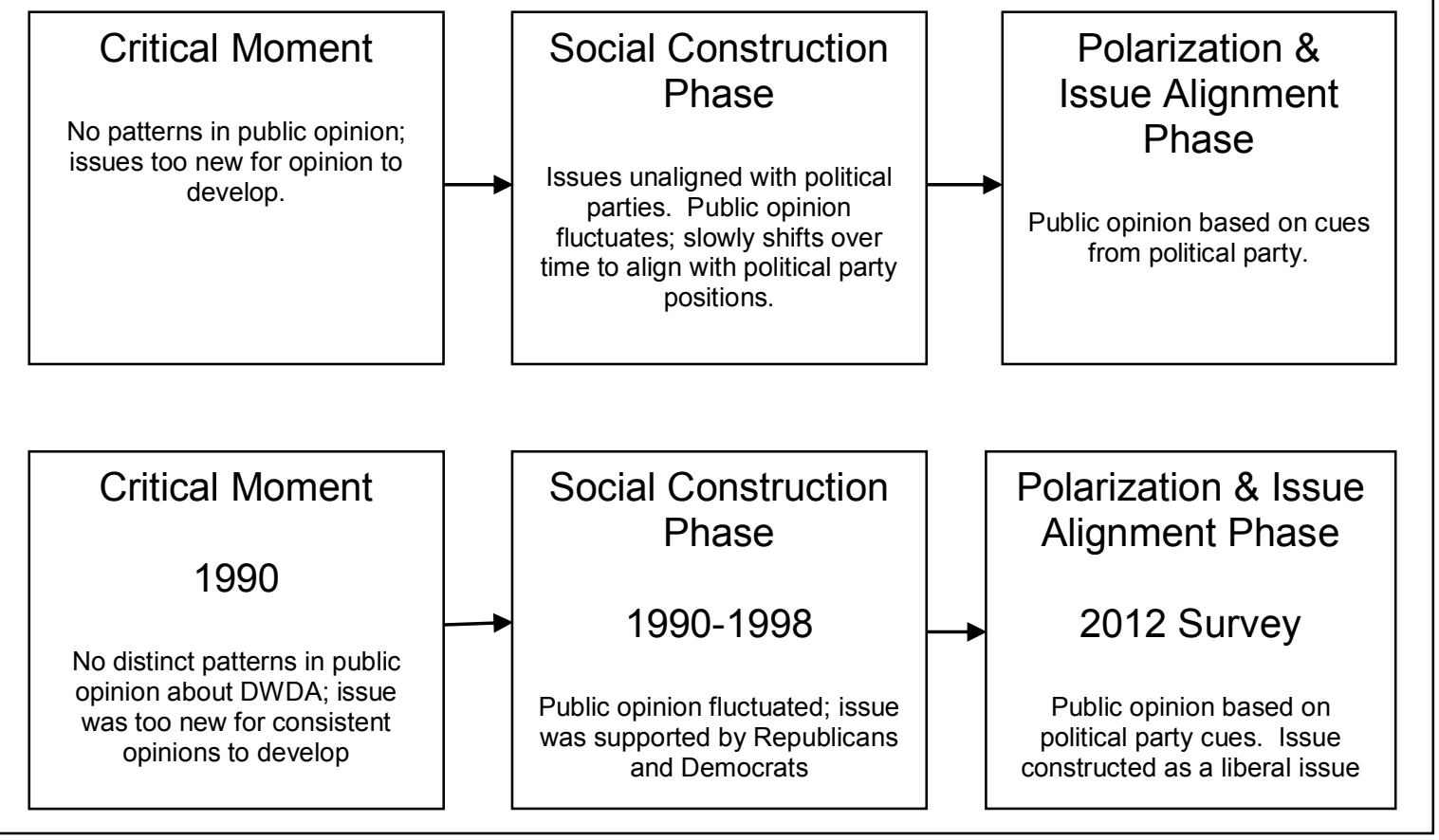

media outlets, support and opposition became more polarized. According to a memo from Fairbank, Maslin, Maullin, and Associates to the leaders in the Oregon Right to Die PAC (personal communication, October 17, 1993), support for I-119 fell among both Democrats and Republicans during the period between April and November 1991.

Support from Democrats decreased 6\% during this time period, while support from Republicans fell 16\%.

Unfortunately, this is the only polling evidence available from the appropriate time frame to examine Stimson's second factor (2004). Results from this polling roughly mirror the situation posited by Issue Evolution Theory, but there is not enough information to draw any substantial conclusions. 
There may be more evidence to explore the Issue Evolution Theory's third factor, which suggests that public attitudes regarding controversial topics become more polarized over time. In a September, 1993 poll conducted prior to the first ballot initiative in Oregon (Measure 16), 69\% of Democrats indicated that they definitely or probably would vote yes on the ballot measure question, "Shall the law allow terminally ill adult patients the voluntarily informed choice to obtain a physician's prescription for drugs to end life?" (Fairbank, Maslin, Maullin, and Associates, 1994). Fewer Republicans reported that they would vote definitely or probably yes on the same question $(44 \%)$.

In exit polling conducted by CNN (2008) on November 4, $2008(n=1,233)$ for the Washington Death with Dignity ballot initiative (I-1000), the ideological cleavage between Democrats and Republicans was bigger than it was in Oregon in 1993. The measure was supported by $74 \%$ of Democrats and $35 \%$ of Republicans. The split was even larger when the question of ideology was conceptualized along the lines of liberal and conservative $-81 \%$ of individuals who identified as liberal voted for the death with dignity measure, while only $33 \%$ of individuals who identified as conservative voted for the measure.

Different groups in the death with dignity movement have conducted proprietary polling over time measuring support for the issue from Republicans and Democrats. While the questions were not asked in the same manner every time over the 20 year time 
span, public opinion has become more split on partisan lines, with the biggest cleavage occurring in the first few months after the "critical moment" of 1990.

Overall, Stimson's (2004) framework suggests political affiliation or political party affiliation is the main factor contributing to public opinion on social issues, and he argues that after a period of time, individuals take cues from political parties about voting positions on controversial social issues. This study explored the role of political affiliation in predicting public opinion, as posited by Stimson, but it was not be an outright test of Stimson's framework. Other factors, which Stimson omits from the framework were explored, including various attitudinal issues and demographic characteristics in predicting current support for DWDA.

\section{Factors in the Proposed Study}

Stimson's Issue Evolution Theory (2004) suggests that political ideology will be the main factor contributing to public opinion about death with dignity. If his theory applies, early measurements of public opinion will not fall neatly along party lines. More contemporary surveys of public opinion will indicate that voters support death with dignity along party lines. Stimson does not explore factors other than political affiliation as indicators of support or opposition; however, studies exploring public opinion on social issues like abortion and stem cell research illustrate other factors contribute to public opinion.

Political ideology as the main factor in this study. Stimson's main contribution (2004) to the body of knowledge about polling focuses on issue alignment. He examined 
over 50 years of polling data on seven domestic issues: taxation, education, health care, cities, environmental issues, welfare, and race. When Stimson overlaid the 50-year history of public opinion polling regarding these issues, an interesting pattern arose. The issues were connected; support and opposition for the seven issues fluctuated together in similar patterns. When they were plotted on the same graph, the lines representing public support for each of the different issues were parallel. Even more interesting, the vacillation roughly coincided in a negative direction with the political party in control of the nation. When a majority of major officeholders were Democrats, public opinion on the seven issues moved toward more conservative attitudes (support for smaller government, less taxation, and conservative views on social issues). Conversely, when Republicans ran the country public opinion shifted toward more liberal views (support for bigger governments, increased taxes to fund social programs, and liberal views of social issues). The issues were tied along political affiliation lines, and the party in power was predicted to lose support for its ideological view on the seven domestic issues.

Stimson (2004) notes that novel contemporary issues are difficult to assessopinions about gun control, abortion, or the death penalty may or may not follow this trend. It is not until the full 50 years of polling data were available about these issues that the patterns emerged clearly. Death with dignity is one of these contemporary issues. There is concrete polling data available since 1991, but 50 years of data do not exist. For this proposal, I examined whether death with dignity fell into issue alignment with the other topics - with public support fluctuating in a parallel line with the other issues, 
primarily along the lines of political ideology. Hence, one of the main factors I have chosen to examine was political ideology. I hypothesized that Oregonians' opinions about death with dignity would become more polarized over time and that political affiliation would be a significant factor in predicting public attitude toward the issue.

Many recent public opinion studies of controversial social issues have identified political affiliation as a main factor in predicting public support. Hicks and Lee (2006) found that a conservative ideology and Republican affiliation predicted anti-gay attitudes in their regression model $(\mathrm{F}=55.99, \mathrm{p}<.01 \mathrm{n}=1,136)$. Similarly, using logistic regression, Haider-Markel and Joslyn (2008) illustrated political affiliation predicted affect toward gay men and support for marriage rights. Studies by both Nisbet (2005) and Ho, Brossard, and Scheufele (2008) illustrated that ideology was a significant predictor of support for stem cell research. Finally, Facchini and Mayda (2008) found that "political affiliation with the right" was negatively correlated with immigration reform opinions allowing for more open borders. The studies by Hicks and Lee, and Haider-Markel and Joslyn were explanatory studies, utilizing advanced statistical modeling techniques. The stem cell research was exploratory in nature and used descriptive statistics primarily. More advanced analysis is needed on this issue, but these early studies coincide with theory and with studies on other issues.

\section{Other demographic characteristics as important factors to explore. Many}

other variables are commonly used in studies about public opinion. Age, education level, religiosity, income, and gender have all been shown to be correlated to public opinion on 
a variety of controversial social issues, including stem cell research, abortion, gun control, attitudes toward lesbian, gay, bisexual, and transgender (LGBT) individuals, and the death penalty. Salience is construed on occasion as a mediating factor-when an issue is identified as having "high importance" to an electorate, then laws are frequently enacted that are in line with public opinion. When an issue is of little importance to an electorate, then policy may not be enacted, even if the public is very supportive of the issue.

Age. The age-stability hypothesis articulated by Anderson and Fetner ${ }^{1}$ (2008) suggests individuals form opinions early in life and rarely change opinions as they age. According to Anderson and Fetner, this hypothesis "claims that people change their minds little as they age," (p. 312). Furthermore, the hypothesis posits that individuals from older generations tend to have more conservative opinions on social issues than those from younger generations, who tend to be more tolerant. Indeed this hypothesis has been confirmed in many studies of public opinion. Branton (2003) examined 50 ballot initiatives in 20 states from the 1992, 1994, and 1996 elections, including the 1994 death with dignity ballot initiative in Oregon, and she found that age is associated with voting patterns on social issues. Older voters were more conservative than younger voters.

\footnotetext{
${ }^{1}$ Anderson and Fetner use the term age-stability hypothesis. Some researchers may identify it as "agestability theory."
} 
While examining public opinion about LGBT issues, Hicks and Lee (2006) concluded that age was a significant part of two different models predicting anti-gay attitudes. Older individuals in these models exhibited higher levels of anti-gay attitudes (a more conservative position) than younger individuals. Haider-Markel and Joslyn (2008) explored seven different models of public opinion regarding LGBT individuals (e.g. support equal rights and homosexuality is morally acceptable), and age was a significant predictor in five of the models. Younger respondents were more likely to support LGBT issues than older respondents.

Age was a non-significant demographic factor in studies of public opinion related to immigration policy, abortion, and the death penalty. Facchini and Mayda (2008) constructed two separate models to describe pro-immigration attitudes, and age was not a significant predictor in the models. Wiecko and Gau (2008) explored the factors which contributed to the likelihood that an individual would self-identify as both opposed abortion and to the death penalty. Age did not contribute significantly to their models.

Support for human embryonic stem cell research is socially constructed as a more liberal concept, and the age-stability hypothesis fails in two studies of public opinion on this controversial topic. Using hierarchical multiple regression to predict support for stem cell research, Ho, Brossard, and Scheufele (2008) found that those who are older were significantly more likely to support stem cell research than younger respondents. Nisbet (2005) came to the same conclusion. The failure of the hypothesis on this issue may be explained by the topic under consideration — older individuals may 
disproportionately reap the benefits of stem cell research because they may be more affected by the diseases that stem cell research has the potential for curing. Death with dignity may enjoy more support among older Oregonians for this same reason; they may be more impacted by the possibility of a physician-hastened death than a younger, healthier population.

Income and education. Income and education are frequently used as predictor variables in gauging public opinion. Generally, they are less important than age and political affiliation, but they are significant predictors in many models. In the study of anti-gay attitudes, Hicks and Lee (2006) found education was a significant predictor, but income was not, in two different models. Those with more education were less likely to display anti-gay attitudes. Similarly, Anderson and Fetner's (2008) model featured education as a significant predictor of tolerance of LGBT individuals in a 20 -year study of Canadians and Americans. They did not include income in their study. Haider-Markel and Joslyn (2008) used demographic variables to build four models describing support for LGBT rights. Education was a significant predictor in all four models, with higher education leading to more support for LGBT rights. Again, income was not included in this study.

Education and income have been found to be significant predictors in models predicting public support for human stem cell research (Ho, Brossard, \& Scheufele, 2008; Nisbet, 2005) and immigration policy allowing individuals to more easily and frequently become citizens of the United States (Facchini \& Mayda, 2008) with higher levels of 
income and higher education predicted more support for stem cell research and loosening of federal immigration restrictions. Wiecko and Gau (2008) found education to be a significant predictor of a respondent self-identifying as both opposed to abortion and supportive of the death penalty, while socio-economic status was not significant in the model.

Religion. Many studies look at religiosity as a predictor of public opinion on controversial social issues. It is hypothesized that members of the general public look to authority figures as a source of guidance on moral issues. Three studies of attitudes toward LGBT individuals found religiosity (the frequency of church attendance) to predict pro-LGBT attitudes, with those attending church espousing more negative attitudes (Hicks \& Lee, 2006; Anderson \& Fetner, 2008; Haider-Markel \& Joslyn, 2008). In two of the studies, religiosity was the strongest predictor variable in the model.

Both Nisbet (2008) and Ho, Brossard, and Scheufele (2008) found that religion was a significant predictor of support for human embryonic stem cell research. The relationship was inverse, with those attending church more often demonstrating less support for stem cell research than infrequent churchgoers. Similarly, Facchini and Mayda (2008) found an inverse relationship between religiosity and pro-immigrant attitudes. The more the respondents in this study attended church, the less likely they were to display pro-immigrant attitudes.

Attitudinal variables. Four attitudinal factors play out commonly in the popular press and media during times of controversy about death with dignity, but effectuate a 
scant appearance in academic parlance. They include ideas about death with dignity as an individual right, opinions about the role of government in end-of-life care decisions, ideas about suicide, and the role of physicians in the implementation of death with dignity policies. The most likely reason for their exclusion is their role as framing devices, as defined by Snow (2013, n.p.), "Framing, within the context of social movements, refers to the signifying work or meaning construction engaged in by movement adherents." These four attitudinal variables are used by proponents and opponents alike to construct meaning and convey messages to their respective adherents, and their impact was explored in this study.

For example, opinions about whether or not (and how) the government should take a role in establishing processes for patients and physicians to follow when hastening death were common during the Oregon campaigns in 1994 and 1997. A primary argument put forth by the chief petitioners of the Oregon Death with Dignity ballot initiative was, "Get government out of this most personal decision of a dying person," (See Arguments in Opposition, Voters' Pamphlet, 1997, p. 10). Angell (1999) explored attempts by Congress to restrict Oregon's law, arguing some of the opposition was based in a belief that the law was a "...meddlesome encroachment on the practice of medicine," (p. 1924). Distilling these arguments, one might safely assume proponents of death with dignity argue that federal or state bans on the practice are tantamount to government intrusion in a personal decision; opponents assert that death with dignity laws represent a 
state-sponsored intrusion into the practice of medicine. These are two "frames" for the same idea: the appropriate role of government.

The idea of death with dignity as an individual right is the least explored of these attitudinal factors, but perhaps the most relevant to social work. Mackelprang and Mackelprang (2005), in their examination of contemporary end-of-life care issues in social work, conclude that end-of-life decision-making must be explored through a social justice lens. Their exploration of the idea is limited, comprising only one or two sentences. Norton and Miller (2012) conducted a qualitative study about death with dignity with hospice social workers, and ideas about social justice and individual rights did not emerge as a thematic pattern during their interviews.

Conversely, of the four attitudinal variables, opinions about the role of physicians in hastening death are explored most commonly in academic journals. Allen et al. (2006) stress that the act of physician-hastened death (by prescription) is controversial because it suggests a violation of the Hippocratic Oath. Angell (1997) represents the other side of the argument, asserting that once healing is no longer possible, the physician is obligated to take the role of ending or alleviating suffering. Duncan and Parmelee (2006, p. 266) ask "What role, if any, should physicians play?" in their exploration of polling data from 1947-2003. A recent editorial in the New England Journal of Medicine called for removing physicians from the process and establishing a national or state independent authority to make the determination of eligibility and offer medication (Julian, Prokopetz, and Lehmann, 2012). There are diverse beliefs about the appropriate role of physicians 
in the practice of death with dignity, running the gamut from opposition to obligation, and one of the predictor variables in this study examined these beliefs.

Suicide, too, is a controversial subject, frequently addressed in relationship to death with dignity. For opponents, moral opposition to the practice may be rooted in religious teachings which posit suicide as an unpardonable sin. For supporters, a prescription provided under the auspices of death with dignity may act as a deterrent to violent suicides (Angell, 1997). More frequently, however, supporters reject the word suicide because it connotes the taking of one's life by a person who does not want to live, while those who choose death with dignity want to live, but are going to die anyway (Quill, 2012). The physician's prescription allows them to choose the timing and manner of their death (Bruce, 2012). These conceptualizations of suicide are profoundly different, and this study explored opinions about suicide as a predictor of support.

\section{Research Questions}

In this study, I explored contemporary public opinions about the Oregon Death with Dignity Act and examined the factors which have led to changes in public opinion over time. There was one primary research question for this study and several follow up questions. The research questions were:

- How much support does DWDA have among Oregonians today?

- What are the patterns of support in specific subpopulations of Oregonians (e.g. Catholics, people of color, Republicans)? 
- How do the aggregate results from polling in 1994 and 1998 compare to contemporary levels of support in Oregon?

- What factors have contributed to changes in public opinion?

- What factors predict current support for Death with Dignity?

I hypothesized that a substantial majority of Oregonians would report that they support the law today. Furthermore, I hypothesized that political affiliation would be the strongest factor contributing to current support for the issue —-with Democrats displaying more favorable opinions that Republicans. I hypothesized that older individuals, those who exhibit less religiosity, and more educated individuals would demonstrate higher levels of support. I hypothesized that those who report that the issue is important would display higher levels of support than those who report that the issue is not important. In comparing the results from the contemporary poll, I expected substantial growth in public support with factors such as the lack of documented abuse, the decadelong history of successful implementation, and the mere existence of the law reported by respondents as reasons for changing their opinions about DWDA. I anticipated that few individuals would report that their opinion had changed from "support" to "oppose." 


\section{Chapter 3 \\ Methods}

This project was a cross-sectional study conducted with registered Oregon voters using a mixed mode online-mail-telephone survey data collection plan. There was one primary research question for this study focused on the current status of public opinion about death with dignity. Answers to this question involved an explanatory study using statistical modeling techniques; answers to follow-up questions regarding patterns of support in subpopulations and reasons for opinion change entailed a descriptive study. The research was a joint project conducted for this dissertation and for the Death with Dignity National Center [a 501(c)(3) non-profit corporation] with the data being shared between the two entities. Results from this study were used to meet the requirements of Portland State University's dissertation standards and to help fulfill the education and research components of the mission of the Death with Dignity National Center. The Institutional Review Board at Portland State University oversaw the human subjects' protections process.

\section{Sampling}

One of the chief concerns in political polling is obtaining a random sample of voters who represent typical voters in a particular state or jurisdiction. Non-voters are not of particular interest in political polling (nor in this study) because they may hold different views from the population of individuals who regularly vote on ballot initiatives. The inclusion of non-voters could have skewed the results, leading to findings not generalizable to voters. Obtaining a random sample of voters has become more 
difficult in recent years due to changes in telephone usage patterns, as increasingly, some individuals operate in cell-phone-only households (Dillman, Smyth, and Christian, 2009). In order to generalize the results from this study to all Oregon voters, a sampling strategy was launched which was representative of all households, not just those who use telephone landlines.

A national firm specializing in the provision of voter telephone lists for polling firms, political candidates, and non-profit political organizations, Artistotle, Inc., supplied a simple random sample of 1,800 Oregon voters for the project. In order to maintain upto-date voter records in all states, Aristotle obtained voter files from Secretaries of State and county boards of election and matched the files to census data and information from telephone books with appended telephone numbers. Aristotle reported its collection of Oregon voter files was continually updated in this manner, and the list of 1,800 registered voters obtained in November 2011 represented the sampling frame for the study.

\section{Data Collection}

There were two waves of data collection stretching between February and August 2012, each offering respondents the opportunity to respond online, by mail, or by phone. Initially, 1,300 respondents received a letter inviting them to participate online using an individualized PIN. The letter provided information about the types of contact participants would receive through the course of the study, an informed consent statement, instructions for opting out, and the opportunity to receive the survey in a 
Spanish language version. Those who completed the survey online were entered in a drawing for one of two $\$ 100$ gift cards to a grocery chain with outlets throughout Oregon.

Two weeks after respondents received this initial letter, they received a copy of the survey instrument (see Appendix) in the mail, along with another explanatory letter. Both mailed letters identified the project as a dissertation research study operating under the auspices of PSU and the Death with Dignity National Center. The letters arrived under the cover of the Regional Research Institute (RRI) and the School of Social Work at PSU, and contained a postage paid envelope to return the surveys to RRI.

Four weeks after respondents received the survey instrument in the mail, they received telephone calls inviting them to participate by phone. The phoning project lasted approximately two months. When this first wave of data collection was in the phoning stage, a second wave was launched with the remaining 500 individuals from the sample. The same steps were followed during both rounds of data collection.

During the first round of mailed surveys, the printer made an error, printing the same PIN code on each of the 1,300 mailed surveys. This error necessitated a change in protocol for the phoned survey modality in an effort to eliminate duplication. Two additional questions were added to the telephone script: one asking if the respondent had already completed the survey and the second asking the respondent's city.

The telephone surveys were conducted by two paid telephone interviewers who were employed by the Death with Dignity National Center. Interviewers participated in a training session prior to conducting surveys in order to reduce error in the data collection 
process. The interviewers were new employees to the organization and were screened regarding their opinions about DWDA. Those with extreme views on the issue (either for or against) were not retained as interviewers. A portion of the training was focused on strategies for interviewers to remain neutral on the issue during the interview. The training was conducted by two individuals - the investigator and the employees' supervisor - with a focus on reducing systematic error associated with social desirability bias and an acquiescent response set. Because DWDA has been a law since 1994, respondents may have felt compelled to suggest they have always supported or opposed the law, and the interviewers were trained to deliver the questions from a position of neutrality to mitigate systematic error.

Interviewers received training in the specifics of delivering the survey instrument via the telephone. Particular attention was paid to skip patterns and answer rotations in the instrument so that interviewers did not introduce systematic error into the data collection process by inaccurately collecting data from respondents. During the training process, interviewers conducted mock interviews in order to demonstrate competence in data collection. For every 25 hours of data collection for each interviewer, the investigator and the employee's supervisor monitored 1 hour of telephone calls in order to ensure the survey instrument was being executed properly and to reduce error.

The online version of the instrument was constructed using Qualtrics, an online survey provider. Potential respondents were directed to a website via the mailed correspondence and entered a PIN code to launch the online survey. After entering the 
PIN, the first screen reflected informed consent information, and the following screens contained the survey. The Qualtrics online version of the survey was available in English and Spanish with questions and responses identical to those from the mailed instrument. Additional transition statements were included to ensure the survey flowed properly in the online milieu.

The survey instrument itself was a 26-item questionnaire (see Appendix) containing screening questions to determine if the respondent was a voter. Following the screening questions, the questionnaire asked how the respondent would vote on a death with dignity ballot measure today. It asked five attitudinal questions about physicians, religion, and end-of-life care that are commonly associated with support. It contained a series of questions in a skip pattern meant to determine if the respondent had changed his or her opinion on the issue over time, and it concluded with demographic questions. The entire questionnaire took between 12 and 15 minutes to complete on the phone, and 7-8 minutes online. Testing indicated the paper version took between 10 and 15 minutes to complete, depending on the skip patterns relevant to the particular responses. Telephone interviewers completed the questionnaire on paper, and the investigator entered the raw data into SPSS for analysis.

The survey instrument was developed using questions from prior polling. A draft instrument was tested with six individuals who represented some of the diversity of opinion expected from Oregonians responding to the survey. The respondents were 
dissimilar from each other in the demographic variables of race/ethnicity, age, gender, religiosity, income, and education.

The testing process involved reading the survey questions from the online Qualtrics survey to each participant and soliciting responses to each survey question. Additionally, the six individuals were asked to interpret the meaning of each question and asked to describe the thought process of deciding which answer to give. The sessions were recorded, and there was a note taker present; the sessions lasted about an hour.

The notes and recorded interviews were used to determine if any questions were confusing to respondents. Substantial changes were made to the questions about familiarity with the law and opinion changes, as the wording in the draft was confusing to a majority of the test survey volunteers. Minor issues were addressed during cognitive testing, too, including an erroneous skip pattern and the absence of intended randomization on the response set of one question.

The cognitive testing process was helpful in two ways. First, it demonstrated, for the most part, respondents were able to understand the questions and give a solid, wellreasoned argument defining the content and context of their answers. The volunteers' interpretations of the questions suggested the information matched the type of information the survey sought to elicit. In the two cases where it did not match expectations, the questions were clarified.

The process was helpful in an unexpected manner. It provided guidance in the development of the training plan for those who delivered the phoned survey by revealing 
the sections in the survey that were difficult to manage. Specific instructions about these questions were included in the interviewer training, and transition statements were developed to smooth out the interview process.

The research protocol and consent statements were approved by the Institutional Review Board of Portland State University. A consent form explaining the purpose, procedures, risks, safeguards and benefits of the study was available for each participant, regardless of response modality, and his or her verbal consent to participate was obtained prior to administration of the survey. For the protection of human subjects, data was stored in a locked filing cabinet and in password-protected computer files at the offices of the Death with Dignity National Center. The data collection process was confidential, as unique identifiers were used throughout the process. After the raw data were entered into SPSS and reviewed for accuracy, all of the individual questionnaires were destroyed and/or deleted.

\section{Design and Variables}

The study represented a cross-sectional design with one group of current Oregon voters surveyed in 2012. It was both descriptive and explanatory in nature, as the findings were used to explain and predict current public opinion about death with dignity and to explore the reasons why public opinion changed over time. The aggregate results from two prior surveys of Oregon voters were used in the analysis for comparison purposes, and results from the current study were used to examine systematically factors which led to change in public opinion over time. 
Outcome variable. For the primary research question, which examined the current level of support for death with dignity, the outcome variable was operationalized by reading the text of the 1994 ballot question to respondents and asking how they would vote if the measure were on the ballot today. The language appearing on the ballot in 1994 was, "Shall the law allow terminally ill adult patients the voluntarily informed choice to obtain a physician's prescription for drugs to end life?" The response set was ordinal with the available responses ranging from definitely yes, probably yes, probably no, to definitely no. This outcome variable was operationalized in the same manner in the 1994 and the 1998 survey instruments used for comparison purposes in this study. The question was asked in this way to avoid the language of "death with dignity" which is used by proponents as messaging tool to gain support for the issue. Similarly, the language of "physician-assisted suicide" which is used by opponents as a messaging tool to enhance opposition was avoided.

While measured with an ordinal response set, the outcome variable was collapsed to a dichotomous support/oppose variable during analysis. The decision to collapse the responses was made for several reasons: ease of interpretation of the findings, relevance to policy-practitioners, and to reduce the number of cells in contingency table or chisquare analysis.

A secondary research question explored the factors which led to opinion change in respondents. This was a somewhat difficult outcome variable to examine because of the potential for recall bias impacting the answers and leading to systematic error. The 
respondents were asked to think back to the first time they encountered the issue, and then asked to answer a question about whether or not they had changed their opinion on the issue since that time. There was not a comparable former study focused on the reasons why individuals change their opinion on death with dignity, so little guidance in successful methods for exploring this issue was available. Respondents were asked to provide a short statement about why their opinions changed over time, and prompts were available.

The answers to these open-ended questions were categorized using a coding process, and these responses represented the outcome variable for this secondary research question, "What factors have contributed to changes in support?" Without prior research in this area, it was impossible to estimate the number of respondents who might change their opinion relevant to this line of questioning. Ultimately, the subsample of respondents indicating they had changed their opinion was too small for adequate quantitative analysis and the answers solicited too short for an appropriate qualitative analysis.

\section{Predictor variables.}

Demographic variables. A variety of demographic predictor variables were analyzed in this study. Stimson's model suggests that political affiliation would be the main factor predicting support for death with dignity. The concept of political affiliation has different dimensions, as it can be examined as affinity toward a particular party or placement on a continuum ranging from conservative to liberal. In recognition of the 
different indicators for the variable political affiliation, it was operationalized two ways: by asking individuals about their political party affiliation (response set included Mostly Democrat, Leaning Democrat, Completely Independent, Leaning Republican, Mostly Republican, and None) and by asking individuals how they identify politically (Conservative, Middle of the Road, Liberal, Libertarian).

In addition to political affiliation, this study hypothesized religiosity would impact a person's opinions about death with dignity. Like political affiliation, religiosity is a variable with many dimensions. The questionnaire asked respondents to identify categorically the religion with which they are most closely affiliated. The response categories were Catholic, Jewish, Protestant, Mormon, none, and other. Another way to explore religiosity is to ascertain how often an individual attends religious services, and the survey instrument asked this question. The response categories were ordinal with a range from "once a week or more" to "never."

The other demographic variables explored as predictor variables included gender, age (calculated by asking what year the respondent was born), and income. Income was operationalized in ordinal level categories using $\$ 15,000$ increments. Race was conceptualized as a categorical variable with the response sets of White/Caucasian, African American or Black, American Indian, Asian, Native Hawaiian or Pacific Islander, Hispanic or Latino, two or more races, and other. Education was hypothesized as a possible predictor of support for death with dignity in this study, and it was 
operationalized on an ordinal scale with six response categories ranging from "grade school or some high school" to "graduate or professional degree."

Issue salience. Salience is a non-demographic variable used as a predictor of support for death with dignity. It was assessed using one question: "how important to you is this issue of whether or not to allow terminally ill adult patients the voluntarily informed choice to obtain a physician's prescription for drugs to end life?" The respondents were offered a five-point response ordinal scale ranging from not important to very important. This question occurred early in the questionnaire and was asked using ballot title language (without the words "death with dignity" or "physician-assisted suicide") so participants could offer the most optimal non-biased response.

Attitudinal variables. Along with demographic characteristics, certain attitudinal issues are relevant in predicting support for death with dignity. They include:

perceptions about the appropriate role of government in regulating or establishing death with dignity, ideas about death with dignity as a personal right, opinions about a physician's role in the process, and beliefs about suicide.

\section{Data Analysis Plan}

Data was analyzed using the SPSS Predictive Analytics Software (SPSS) data analysis program. The investigator entered all of the data collected by the telephone interviewers, as well as the responses to the mailed survey, into Qualtrics and transferred the data into SPSS for analysis. 
Univariate analysis. Univariate analysis was conducted with each predictor and outcome variable for two primary purposes: to describe the typical value for each variable, both in terms of central tendency and dispersion and to answer the study's primary research question. In terms of central tendency, means, medians, and modes were calculated for all continuous variables while frequencies were explored for categorical variables. To explain the dispersion of variables, standard deviations and ranges were calculated. Reported values for each variable were chosen based on the value most accurately and appropriately describing the typical case.

Univariate analysis was adequate to answer the primary research question: "How much support does DWDA have among Oregonians today;" bivariate descriptive statistics were used to answer the follow-up question "How do aggregate results in polling from 1994 and 1998 compare to contemporary levels of support in Oregon?" Because a portion of the research questions were analyzed using multivariate methods, univariate and bivariate inferential analysis was conducted to assess the degree to which the variables met the assumptions for multivariate analysis. This preparatory work and assumptions for model-building are discussed in more detail below.

Bivariate analysis. Bivariate inferential analysis was used to answer the secondary questions "what does support look like in specific subpopulations of Oregonians (e.g. Catholics, people of color, Republicans)?” Similarly, bivariate inferential analysis was used to explore the associations between the main predictor variables of interest and the outcome variable, support for death with dignity. Because 
support for DWDA was measured at the ordinal level, but could be easily converted to categorical level data, chi-square was most common measure of association calculated and reported for this project. To convert support for DWDA from an ordinal level variable to a dichotomous variable, SPSS was used to re-code the original variable with all respondents who were both "definitely yes" and "probably yes" re-coded as "supporters" and all "definitely not" and "probably not" respondents re-coded as "nonsupporters."

Chi-square was chosen as the method of analyzing the strength of association over formulas appropriate for ordinal level variables (such as Somer's d and tau b) for several reasons. The primary reason focused on the ability to compare results over the waves of data collected in 1994 and 1998. Chi-square was chosen because of the manner in which support was calculated reported in the prior polls — as a dichotomous variable. These polls were conducted to ascertain vote for a specific ballot measure; hence, the pollsters were interested in forcing the voters to choose "support" or "oppose," much like they would be forced to choose on a ballot. In calculating and reporting this outcome variable as dichotomous (using a chi-square), the choices from the earlier polls were imitated. A chi-square measure of association was calculated for political affiliation (as measured in the categories liberal, conservative, middle of the road and libertarian) and support for DWDA. Similarly, chi-squares were calculated for religiosity (by collapsed categories) and support for DWDA; education (again, by collapsed categories) and 
support; and salience and support. The standard $p<.05$ level of significance was used to evaluate statistical significance.

Before the chi-square tests were run, the data was assessed regarding the degree to which it met the assumptions for chi-square. Some of the assumptions for chi-square explored include: a random sample with individual measurements independent of one another, adequate sample size, and nominal level data. SPSS was used to determine adequacy of the sample and cell sizes; and none of the data failed chi-square assumptions because the outcome variable was collapsed, leading to smaller table sizes, and larger cell sizes.

Multivariate analysis. Multivariate analysis was used to answer "What factors predict support for Death with Dignity?" The model-building analytic formula was binary logistic regression. The outcome for binary logistic regression is a probabilistic regression equation; the quantity to the left of the regression equation is called the logit, and it refers to the $\log$ of the odds of an event occurring. Mathematically, when this logit is exponentiated, it produces an odds ratio. The odds of an event occurring is a ratio of the proportion of people experiencing the event to the proportion of people who do not experience it; the odds ratio is the ratio of the odds occurring in one group of individuals to the odds of it occurring in a different group. The odds ratio is a measure of effect size, and an odds ratio of one suggests the event is equally likely in both groups; if it is greater than one, the event is more likely in the first group (the numerator); less than one, and the 
event is more likely for the second group (the denominator). Both odds and odds ratios were calculated in this analysis.

Originally, ordinal logistic regression was planned as a data analysis strategy, but it was rejected because the data failed to meet the parallel lines assumption. The parallel lines assumption is a statistical test to determine if all of the regression lines produced by multiple equations (three in this study) are parallel. In ordinal logistic regression, it is assumed that the regression lines are parallel for each level of the outcome variable, and this assumption was tested using a chi-square test of parallel lines, whereby a nonsignificant result is desired. The negative log-log link did not correct the non-parallel nature of the lines, so the combination of categories of the outcome variable was the most desirable option.

As an added benefit, binary logistic regression offered a more clear interpretation during discussion, increasing the utility of the results for social work policy-practitioners who are more likely to engage with odds ratios and predicted probabilities for the two categories of support and oppose than for four categories covering a range of support to oppose.

Model-building and testing fit. Three models were produced: one exploring demographic variables significant in bivariate analysis (church attendance and political affiliation), another examining the four attitudinal variables from the survey, and a third containing all six of these variables entered in two steps (demographic variables first, followed by attitudinal). In order to assess the model fit, the likelihood ratio tests were 
produced. This test compared the intercept-only model (the null hypothesis) to the model with predictors. A model with good fit is significant in this test, and the null hypothesis that the model without predictors is as good as the model with predictors was rejected. In addition, a chi-square goodness of fit test called the Hosmer-Lemeshow test was used to assess the model's fit. For this test, a non-significant finding, or large significance levels, was desirable.

Prediction equations. After assessing the model's fit, the process proceeded with examining prediction equations. Binary logistic regression produces a probabilistic prediction equation, and this equation was used in the analysis to explore individual response scenarios associated with predictor variables (a self-identified Conservative rare churchgoer vs. a self-identified Moderate frequent churchgoer). SPSS uses the equation to produce odds ratios which were reported in the findings.

"Support" was planned as the reference category, meaning the prediction equation would be used to calculate the probability of "support," rather than oppose. Similarly, the odds ratios were intended to be calculated using the supporters as numerators, or the category of interest. Because a majority of respondents were "supporters," the odds ratios returned smaller numbers, making the interpretation and discussion more difficult. The inversion of the equation, switching the reference category to oppose, produced odds ratios more usable for social work policy-practitioners. As applied, the inversion meant the discussion could proceed by stating one group was five times more likely to oppose, 
rather than .2 times more likely to support than another group; results which are more understandable in everyday use.

Effect size. Model effect size cannot be measured using $R$-square statistics used in OLS regression, and there are no analogous "percent of variance explained" statistics for ordinal logistic regression. Rather, model effect size can be evaluated using the Cox and Snell coefficient or the Nagelkerke $R$-square (which does not have a percent of variance explained interpretation in this context). However, Hosmer and Lemeshow (1989) caution against the use of the Pseudo R-square statistics because mathematically they are expressions of the likelihood ratio tests already report (p. 149), and thus, they were not reported for this study.

Assumptions. The key assumptions for OLS regression (linearity, homoscedasticity, normality, and measurement level) do not apply in binary logistic regression (Hosmer and Lemeshow, 1989); however, other assumptions traditionally associated with regression do apply. They include: independent observations, no problems with multicollinearity, and a binary outcome variable. During the modeling process, the issue of assumptions was addressed. There were concerns with multicollinearity, but in the final parsimonious model, the covariates of concern dropped out of the equation.

\section{Review of Data Analysis Plan}

Univariate analysis was appropriate to answer the first research question, "How much support does DWDA have among Oregonians today?” Bivariate inferential 
analysis, specifically the nonparametric chi-square test, was used to answer the follow up questions "What are the patterns of support in specific subpopulations of Oregonians?" and multivariate analysis using logistic regression modeling was used to evaluate the question, "What factors predict current support for Death with Dignity?"

To answer the question "How do aggregate results from polling in 1994 and 1998 compare to contemporary levels of support in Oregon?" data from historic polling and from the current survey were compared. Respondents were asked an open-ended question to address the research question, "What factors have contributed to the changes in public opinion," but the lack of respondents indicating they had an opinion change inhibited analysis. 


\section{Chapter 4 \\ Results}

\section{Response Rate and Margin of Error}

The original list obtained from the sampling firm, Aristotle, Inc., contained a simple random sample of 1,800 individuals registered to vote in Oregon. Through the data collection process, the number of individuals in the final sample was reduced by 20 (3 individuals were deceased, 11 had incorrect address contact information, and 6 reported they were not registered to vote in Oregon). Of the 1,780 individuals in the final sample, 456 responded to the questionnaire either by mail, phone or online, reflecting a response rate of $25.6 \%$.

After cases with missing data on important variables $(n=9)$ and from those who failed the screening questions $(n=5)$ were removed, valid responses from 442 respondents were analyzed.

As noted earlier, a printer's error resulted in some of the responses being sent in without a tracking PIN, thereby rendering it impossible to conclude there is no error as a result of duplicative responses. A total of 159 (36\% of all responses) were submitted anonymously by mail, as a result of the printer's error. Mailing in a completed survey was the most common response mechanism $(n=214 ; 48.4 \%)$, followed by completion of an online survey $(n=141 ; 31.9 \%)$ and by phone $(n=87 ; 19.7 \%)$.

The American Association of Public Opinion Research (AAPOR) mandates the release of margin of error calculations in its Code of Professional Ethics and Practice (2009). The voter file from which the sample of 1,780 records was drawn contains 
information from approximately $2.8 \mathrm{M}$ voters. For this survey, a sample size of 442 out of a population of $2.8 \mathrm{M}$ leads to a margin of error of $+/-4.66$ percentage points at the $95 \%$ confidence level when public opinion is split evenly on any question. The split on the outcome variable in this survey, support for death with dignity, was $80 \%-20 \%$ with $80 \%$ of respondents indicating they would definitely or probably vote for death with dignity if it appeared on the ballot. For this question only, the margin of error is $+/-3.73$ percentage points, 95\% CI [76.27, 83.73], meaning we can be $95 \%$ confident this interval contains the true percentage of those in support.

\section{Characteristics of Participants}

Registered voters in Oregon aged 18 and older who indicated at a minimum they "sometimes" vote on ballot initiatives were eligible to participate. Respondents ranged in age from 21 to 95 . The median $(\mathrm{Mdn}=61)$ and mean $(\mathrm{M}=60.85, \mathrm{SD}=14.91)$ age of respondents was nearly identical, indicating little skewness in the variable age.

Proportionately, women were over-represented among respondents, as more than $60 \%$ of respondents were women (270 of 442 valid responses) and only 159 men (37\%) responded to the survey (see Table 1 for demographic statistics). Given the opportunity in the survey, no individuals responded as trans-identified. Thirteen respondents did not indicate their gender $(2.9 \%)$.

Respondents were asked to self-identify race and ethnicity, and 433 individuals answered the questions. Ninety-two percent $(n=408)$ identified as white or Caucasian. 
Table 1

Frequency distributions describing demographic variables and support for death with dignity

\begin{tabular}{|c|c|c|c|c|}
\hline & $\mathrm{N}$ & $\%^{\dagger}$ & Supporters & Non-Supporters \\
\hline All Voters & 442 & & $355(80.3 \%)$ & $87(19.7 \%)$ \\
\hline \multicolumn{5}{|l|}{ Gender } \\
\hline Men & 159 & $37.1 \%$ & $126(79.2 \%)$ & $33(20.8 \%)$ \\
\hline Women & 270 & $62.9 \%$ & $223(82.6 \%)$ & $47(17.4 \%)$ \\
\hline \multicolumn{5}{|l|}{ Race } \\
\hline $\begin{array}{l}\text { White/Caucasian } \\
\text { African American/ }\end{array}$ & 408 & $92.3 \%$ & $337(82.62 \%)$ & $71(17.4 \%)$ \\
\hline Black & 3 & $0.7 \%$ & $2(66.7 \%)$ & $1(33.3 \%)$ \\
\hline American Indian & 3 & $0.7 \%$ & $2(66.7 \%)$ & $1(33.3 \%)$ \\
\hline Asian & 2 & $0.5 \%$ & $2(100 \%)$ & $0(0.0 \%)$ \\
\hline $\begin{array}{l}\text { Native Hawaiian } \\
\text { or Pacific Islander }\end{array}$ & 1 & $0.2 \%$ & $1(100 \%)$ & $0(0.0 \%)$ \\
\hline Hispanic or Latino & 4 & $0.9 \%$ & $2(50.0 \%)$ & $2(50.0 \%)$ \\
\hline Two or more races & 12 & $2.7 \%$ & $8(66.7 \%)$ & $4(33.3 \%)$ \\
\hline \multicolumn{5}{|l|}{ Congressional District } \\
\hline District 1 & 57 & $20.5 \%$ & $44(77.2 \%)$ & $13(22.8 \%)$ \\
\hline District 2 & 52 & $18.4 \%$ & $46(88.5 \%)$ & $6(11.5 \%)$ \\
\hline District 3 & 56 & $19.8 \%$ & $45(80.4 \%)$ & $11(19.6 \%)$ \\
\hline District 4 & 56 & $19.7 \%$ & $50(89.3 \%)$ & $6(10.7 \%)$ \\
\hline District 5 & 62 & $21.9 \%$ & $48(77.4 \%)$ & $14(22.6 \%)$ \\
\hline \multicolumn{5}{|l|}{ Education } \\
\hline Grade School/ & & & & \\
\hline Some H.S. & 7 & $1.6 \%$ & $4(57.1 \%)$ & $3(42.9 \%)$ \\
\hline $\begin{array}{l}\text { High School Grad. } \\
\text { 2-Year Degree/ }\end{array}$ & 72 & $16.3 \%$ & $57(79.2 \%)$ & $15(20.8 \%)$ \\
\hline Some College & 124 & $28.1 \%$ & $98(79.0 \%)$ & $25(21.0 \%)$ \\
\hline $\begin{array}{l}\text { College Graduate } \\
\text { Some Graduate }\end{array}$ & 102 & $23.1 \%$ & $87(85.3 \%)$ & $15(14.7 \%)$ \\
\hline $\begin{array}{l}\text { School } \\
\text { Graduate or }\end{array}$ & 37 & $8.4 \%$ & $28(75.7 \%)$ & $9(24.3 \%)$ \\
\hline Prof. Degree & 85 & $19.2 \%$ & $73(85.9 \%)$ & $12(14.1 \%)$ \\
\hline \multicolumn{5}{|l|}{ Income } \\
\hline$\$ 10,000$ or less & 13 & $2.9 \%$ & $10(76.9 \%)$ & $3(23.1 \%)$ \\
\hline$\$ 10,001-\$ 14,999$ & 13 & $2.9 \%$ & $10(76.9 \%)$ & $3(23.1 \%)$ \\
\hline$\$ 15,000-\$ 24,999$ & 48 & $10.9 \%$ & $42(87.5 \%)$ & $6(12.5 \%)$ \\
\hline$\$ 25,000-\$ 34,999$ & 39 & $8.8 \%$ & $29(74.4 \%)$ & $10(25.6 \%)$ \\
\hline$\$ 35,000-\$ 49,999$ & 73 & $16.5 \%$ & $63(86.3 \%)$ & $10(13.7 \%)$ \\
\hline$\$ 50,000-\$ 74,999$ & 80 & $18.1 \%$ & $67(83.8 \%)$ & $13(16.2 \%)$ \\
\hline$\$ 75,000-\$ 99,999$ & 46 & $10.4 \%$ & $36(78.3 \%)$ & $10(21.7 \%)$ \\
\hline$\$ 100,000$ or more & 71 & $16.1 \%$ & $62(87.3 \%)$ & $9(12.7 \%)$ \\
\hline
\end{tabular}

Note $^{\dagger}=$ Valid percentages reported 
The second most prevalent response was " 2 or more races" with 12 responses (2.7\%). Each of the other categories had less than one percent of respondents: African American or Black, American Indian, Asian, Native Hawaiian or Pacific Islander. Latinos made up .9\% $(n=4)$ of respondents. Notably, the survey was available in Spanish for all three methods (by mail, online, and by phone), and there were no requests for, nor responses using the Spanish language version of the survey.

For the most part, respondents were distributed equally throughout the Congressional districts in Oregon. The metropolitan Congressional Districts One, Three, and Five contained $20.5 \%, 19.8 \%$, and $21.9 \%$ of respondents, respectively. The large, rural District Two included $18.4 \%$ of respondents. District Four, marked by coastal communities and one of the largest universities in Oregon's public higher education system, is home to $19.8 \%$ of respondents. Congressional District information was obtained from the sampling firm and is not available for the 159 individuals who responded anonymously. No weighting was used to achieve the geographic dispersion in the sample.

Of the 427 participants who responded to the question about educational attainment, 79 indicated they had completed some high school course or were a high school graduate $(17.9 \%)$. A larger portion, $51.2 \%(n=226)$ graduated from a two-year college, took some college classes or graduated from a college or university with a fouryear degree. Finally, 122 individuals (27.6\%) indicated they had taken some graduate level classes or had an advanced graduate degree. 
A higher proportion of respondents skipped the question reporting household income than any other question, but data was obtained from 383 individuals. Of these, $16.7 \%(n=74)$ of participants indicted they had a household income under $\$ 24,999$, while $25.3 \%(n=112)$ had household incomes between $\$ 25,000$ and $\$ 49,999$. The income range \$50,000-\$74,999 included 80 individuals (18.1\%); \$75,000-\$99,999 included 46 individuals (10.4\%). The remaining 71 participants $(16.1 \%)$ reported incomes above $\$ 100,000$.

Table 2

Frequency distributions describing religion and support for death with dignity

\begin{tabular}{|c|c|c|c|c|}
\hline & $\mathrm{N}$ & $\%^{\dagger}$ & Supporters & Non-Supporters \\
\hline \multicolumn{5}{|l|}{ Religious Affiliation } \\
\hline Protestant & 203 & $47.1 \%$ & $153(75.4 \%)$ & $50(24.6 \%)$ \\
\hline Catholic & 68 & $15.8 \%$ & $48(70.6 \%)$ & $20(29.4 \%)$ \\
\hline \multicolumn{5}{|l|}{ Other World } \\
\hline \multicolumn{5}{|l|}{ Religions (Judaism, } \\
\hline Other Faiths & 47 & $10.9 \%$ & $36(77.0 \%)$ & $11(23.0 \%)$ \\
\hline \multicolumn{5}{|l|}{ (Including Mormon) } \\
\hline None/No Affiliation & 100 & $23.2 \%$ & $99(99.0 \%)$ & $1(1.0 \%)$ \\
\hline \multicolumn{5}{|l|}{ Church Attendance } \\
\hline Never/Almost Never & 182 & $42.0 \%$ & $174(95.6 \%)$ & $8(4.4 \%)$ \\
\hline Irregular Attendees & 99 & $22.9 \%$ & $58(95.1 \%)$ & $3(4.9 \%)$ \\
\hline Regular Attendees & 52 & $12.0 \%$ & $76(84.4 \%)$ & $14(15.6 \%)$ \\
\hline \multicolumn{5}{|l|}{ Once a Week or } \\
\hline More & 100 & $23.1 \%$ & $42(42.0 \%)$ & $58(58.0 \%)$ \\
\hline \multicolumn{5}{|l|}{ Evangelical or Born Again } \\
\hline Yes & 112 & $21.0 \%$ & $62(55.4 \%)$ & $50(44.6 \%)$ \\
\hline No & 302 & $79.0 \%$ & $276(91.4 \%)$ & $26(8.6 \%)$ \\
\hline
\end{tabular}

Note $^{\dagger}=$ Valid percentages reported 
Religiosity is a key variable used to predict support for Death with Dignity. This survey used three concepts to characterize religiosity: affiliation, frequency of attendance, and evangelical tradition (see Table 2 for demographics related to religiosity). Of those reporting a religious affiliation $(n=431)$, just under half indicated they were Protestants $(n=203)$, and another 15.4\% (68) self-identified as Catholic. Thirteen individuals (2.9\%) were members of other world religions, specifically Buddhism and Judaism, and 47 selected "other," Mormon or some other faith (10.6\%). Finally, 100 individuals (20.6\%) reported they were unaffiliated with any religion, including individuals who identified as atheist, agnostic or none.

For frequency of church attendance, more respondents (182 out of 433, 42.0\%) indicated they "never or almost never" attended religious services than reported any other category. Approximately one-quarter of participants $(n=99,22.9 \%)$ attended church on an irregular basis (reporting "less than once a year," "about once a year" or "every few months." A few individuals $(n=52,12.0 \%)$ indicated they attended once a month or a few times a month. The second most popular category among respondents was "once a week or more" with 100 individuals (23.1\%) reporting they regularly went to religious services on a weekly basis. If artificially conceptualized as a scale-level variable, the respondents fall into a U-shaped distribution pattern with spikes at the low and high ends of the parabola and few individuals in the middle.

Individuals were asked for a dichotomous response to the question of whether or not they identify as "evangelical" or "born again." Over three-quarters of respondents ( $n$ 
$=302,79 \%)$ indicated they were not evangelical, and $21 \%$ (112 out of 414$)$ were selfidentified evangelicals.

Table 3

Frequency distributions describing political affiliation and support for death with dignity

\begin{tabular}{lllll} 
& $\mathrm{N}$ & $\%^{\dagger}$ & Supporters & \multicolumn{1}{l}{ Non-Supporters } \\
\hline Party Affiliation & & & & \\
Mostly Democrat & 166 & $40.0 \%$ & $158(95.2 \%)$ & $8(4.8 \%)$ \\
Leaning Democrat & 54 & $13.0 \%$ & $44(81.5 \%)$ & $10(18.5 \%)$ \\
Completely Independent & 65 & $15.7 \%$ & $31(78.5 \%)$ & $14(21.5 \%)$ \\
Leaning Republican & 37 & $8.9 \%$ & $26(70.3 \%)$ & $11(29.7 \%)$ \\
Mostly Republican & 74 & $17.8 \%$ & $43(58.1 \%)$ & $31(41.9 \%)$ \\
None & 19 & $4.6 \%$ & $18(94.7 \%)$ & $1(5.3 \%)$
\end{tabular}

Political Philosophy

Conservative

Middle of the Road

$101 \quad 24.5 \%$

$56(55.4 \%) \quad 45(44.6 \%)$

Liberal

$14936.2 \%$

$125(83.9 \%) \quad 24(16.1 \%)$

$\frac{\text { Libertarian }}{\text { Note }^{\dagger}=\text { Valid percentages reported }}$

$157 \quad 38.1 \%$

$151(96.2 \%) \quad 6(3.8 \%)$

Political affiliation was conceptualized in two ways: identification with a particular political party and affinity to a particular ideology (see Table 3 for information about political affinity). Fifty-three percent of respondents $(n=220)$ identified themselves as solid Democrats or leaning to the Democratic Party. Fewer individuals identified with the Republican Party, as 110 (26.7\%) participants identified themselves as "leaning toward" or "completely affiliated with" Republicans. Sixty-five individuals (15.7\%) identified themselves as completely independent, and 19 respondents (4.6\%) said they were unaffiliated with any party. Responses to a question about political ideology fell along a similar distribution with self-reported liberals outnumbering 
conservatives ( $38.1 \%$ to $24.5 \%$ ). More individuals identified with a middle of the road political philosophy $(\mathrm{n}=149,36.2 \%)$ than identified themselves as "completely independent" in the former question.

\section{Representativeness of the Sample}

The state of Oregon does not make public a demographic profile of Oregon voters, so it is difficult to draw conclusions about representativeness of the sample. For example, the median age of all Oregonians as measured by the United States Census Bureau in 2010 was 38.4 (as reported by the Oregon Employment Department, 2011). This number reflects all Oregonians, not those who are over age 18 and registered to vote, so a comparison between the median age of all respondents in the survey and the median age of all Oregonians is not useful in drawing conclusions about representativeness of the sample in terms of age.

There are a few data points available for exploration, those focused on political affiliation, gender, race, and education. Oregon's Secretary of State (2012) reports that $41.9 \%$ of all registered voters in Oregon identified as Democrats and $32.8 \%$ identified as Republicans in July, 2012. Just over 25\% identified as non-affiliated or "Independent," according to numbers reported by the Secretary of State. In this study, 53\% of respondents indicated they were Democrats, 27\% Republicans, and 20\% non-affiliated or Independent. These numbers suggest overrepresentation of Democrats among the respondents. 
According to the U.S. Census Bureau (n.d.), 50.5\% of all Oregonians are female. This number is reflective of all age brackets, not just those over the age of 18 . In the current study, there is a departure from the near 50/50 split in gender with $63 \%$ of respondents identified as female, and 37\% male. In every election since 1984, women have turned out as voters in greater numbers than men, according to the Center for American Women and Politics (2011). The national statistics suggest women should be overrepresented among the respondents, but the available data does not give enough information to draw conclusions about the magnitude of overrepresentation expected.

According to the US Census Bureau (n.d.), the racial make-up of all Oregonians (not just those registered to vote) is $88.6 \%$ white, $8.0 \%$ people of color, and $3.4 \%$ multiracial. In the current survey, $92.3 \%$ of all respondents identified as white, $3.0 \%$ as people of color, and $2.7 \%$ as multi-racial. These numbers suggest there may be underrepresentation among people of color, but they compare two different populations, making it difficult to draw conclusions.

Finally, the US Census Bureau (n.d.) reports $89 \%$ of Oregonians have a high school degree or higher and 29\% have a four-year degree or higher. Among respondents to this survey, $97 \%$ reported a high school degree or higher and 51\% reported a college degree (four year) or higher. These numbers suggest there may be overrepresentation among those with higher levels of education in the sample, but due to the comparison of different groups (registered voters vs. all Oregonians) firm conclusions are difficult. 


\section{Other Descriptive Statistics}

Respondents were asked whether or not they had the opportunity to vote for Death with Dignity in the past. Nearly $2 / 3$ or 285 out of 442 respondents indicated they had voted on the issue in a prior election. Just over 100 individuals $(22.9 \%)$ had not voted on the issue in past elections, and $56(12.7 \%)$ could not recall past voting behaviors or left the question blank. Of those who said they had the opportunity to vote on Death with Dignity in a past election, $73 \%(n=208)$ reported voting for the law, $20 \%(n=57)$ voted against it, and 7\% $(n=20)$ left the answer blank or said they couldn't recall how they voted on the question. This is an interesting pattern, mirroring current levels of support, but problems with recall (Campbell and Stanley, 1963) make interpretation of this response pattern difficult.

\section{Findings}

One primary research question (how much support does DWDA have among Oregonians today?) and four secondary questions were explored through analysis. Discussion of each follows, as does an exploration of preliminary findings used to inform statistical analysis and the model-building process.

Preliminary Findings. Several issues relating to support for death with dignity were explored in the survey, and these issues can be broadly categorized into two groups: perceptions about the law and attitudes impacting support. In the category of perception, individuals were asked about their impressions of how the law was working, how much they knew about the law, and how important the law was to them. Results of $t$ tests and 
means for supporters and non-supporters for these three perceptual variables are depicted in Table 4.

Table 4 Means and Standard Deviations for Perception Variables

\begin{tabular}{|c|c|c|c|c|c|c|}
\hline & \multirow[b]{3}{*}{$t$} & \multirow[b]{3}{*}{ DF } & \multirow{2}{*}{\multicolumn{2}{|c|}{ Supporters }} & \multirow{2}{*}{\multicolumn{2}{|c|}{$\begin{array}{l}\text { Non- } \\
\text { Supporters }\end{array}$}} \\
\hline & & & & & & \\
\hline & & & M & SD & $\mathrm{M}$ & SD \\
\hline Is the law working? & $-12.503 *$ & 395 & 2.03 & .982 & 3.59 & .905 \\
\hline Knowledge ${ }^{\dagger}$ & -1.964 & 113.078 & 2.12 & .630 & 2.30 & .783 \\
\hline Importance & $2.595^{*}$ & 434 & 3.96 & 1.185 & 3.57 & 1.352 \\
\hline
\end{tabular}

Note. $^{\dagger}=$ Failed equal variance assumption using Levene's Test for Equality of Variance $* p<.05$

On a five-point Likert scale with responses ranging from very well, somewhat well, neither well nor badly, somewhat badly, to very badly, participants were asked their impressions of how the law was working in Oregon (Based on what you may have seen or heard, how do think this law is working?). For this question, lower reported values suggested respondents believed the law was working well; while higher values, the converse. The resulting distribution $(M d n=2, M=2.32, S D=1.14)$ was skewed positively with many more individuals reporting the law was working very well or somewhat well $(n=221, M=3.59)$, than somewhat badly or very badly $(n=54, M=$ 2.03). An independent samples $t$ test was used to analyze the difference between supporters and non-supporters in their impressions about how the law was working. There are three assumptions for a $t$ test, and the sample met two of three assumptions: the equal variance and the random sample/independent scores assumptions. The test variable featured a nonnormal distribution, but the larger sample size suggested the independent 
sample $t$ test would be robust to a violation of this assumption (Green and Salkind, 2005). The results of the analysis were significant $t(395)=-12.503, p<.05$, suggesting supporters were much more likely to say the law was working well than opponents. Another perceptual facet explored in the study was knowledge of death with dignity. Respondents were offered a four-point Likert scale (very familiar, somewhat familiar, a little familiar, to not familiar) to answer the question, "How much do you know about the Death with Dignity Act?" Lower response values suggested more familiarity with the law; higher values, less familiarity. The data were normally distributed with a mean of $2.16(\mathrm{SD}=.666)$. The independent samples $t$ test was not significant at the $p<.05$ level, suggesting there is no statistical difference between supporters and opponents on their familiarity with the law.

A final perceptual aspect explored in the survey focused on salience.

Respondents were asked, "How important to you is this issue of whether or not to allow terminally ill adult patients the voluntarily informed choice to obtain a physician's prescription for drugs to end life," replying to a five-point Likert scale ranging from not important, somewhat important, important, quite important, to very important. For this question, lower values were associated with a belief the law was not important, and higher values suggested a respondent believed the law was very important. The analysis revealed a negatively skewed distribution $(M=3.89, S D=1.226)$, with disproportionately more individuals reporting the issue was "very important" than "not important." An independent samples $t$ statistic was calculated to determine if supporters 
and non-supporters maintained significantly different opinions on how important the issue was to them. The statistic was significant at the $p<.05$ level, $t(434)=2.595$. Overall, both groups indicated this was an important issue, but supporters $(M=3.96, S D$ $=1.185)$ were less likely to say this issue was unimportant than non-supporters $(M=$ $3.57, S D=1.352)$

Historically, four attitudinal issues have formed the core disagreement about the issue between supporters and non-supporters: the role of government in establishing or taking away the availability of death with dignity, whether or not this practice should be a right available for terminally ill individuals, the question of whether or not death with dignity constitutes suicide, and the role of physicians in the process. The survey contained one question addressing each issue on a four-point Likert scale with a response scheme running from strongly agree, somewhat agree, somewhat disagree, to strongly disagree (see Table 5). For all four questions, lower response values indicated the respondents were in agreement with the statement, and higher values indicated disagreement.

For all respondents, the mean score on the question "How a terminally ill person chooses to end his/her life should be an individual decision and not a government decision?" was 1.21 with a standard deviation of .561 ; more people agreed with the statement than disagreed. Similarly, more people agreed with the statement, "People in the final stages of a terminal disease should have the right to stop their suffering by 
hastening their death, if they so choose," $(M=1.56, S D=1.013)$. As noted above, lower values indicate agreement with the statements; higher values disagreement.

In regards to the statement, "Regardless of circumstances, suicide is morally wrong and the law should not permit it," more people disagreed than agreed $(M=3.08$, $S D=1.149$ ). With a mean of approximately three, most respondents clustered around the response category of "somewhat disagree."

The mean score of the statement focused on physicians, "In general, doctors should never take part in any activity that would help a patient die," was $3.03(S D=$ 1.105). For this question, lower values indicate agreement with the statements; higher values, disagreement, and most individuals clustered around "somewhat disagree" when asked this question about physicians.

Independent sample $t$ tests were conducted on these four attitudinal issues to ascertain the differences between supporters and non-supporters. The hypothesis that all four would demonstrate a significant difference between means for supporters and nonsupporters was confirmed by the analyses (see Table 5). Supporters were significantly more likely than non-supporters to say the decision to opt for death with dignity was an individual choice, not for governmental interference, and terminally ill individuals should have a right to death with dignity. Conversely, opponents were significantly more likely than proponents to say suicide is morally wrong and physicians should not participate in any activity causing a patient's death. 
Table 5

Means and Standard Deviations for Attitudinal Variables

\begin{tabular}{|c|c|c|c|c|c|c|}
\hline & & & $\underline{\text { Supp }}$ & rters & $\frac{\text { Non- }}{\text { Supp }}$ & rters \\
\hline & $t$ & DF & M & SD & $\overline{\mathrm{M}}$ & $\overline{\mathrm{SD}}$ \\
\hline Role of Government ${ }^{\dagger}$ & $-4.652 *$ & 81.072 & 1.11 & .341 & 1.64 & .993 \\
\hline Individual Right $^{\dagger}$ & $-20.982 *$ & 89.035 & 1.15 & .419 & 3.33 & .917 \\
\hline Physician's Role & $21.399 *$ & 426 & 3.48 & .798 & 1.37 & .798 \\
\hline Suicide & $19.788 *$ & 427 & 3.41 & .788 & 1.49 & .843 \\
\hline
\end{tabular}

\section{The Primary Research Question}

The primary research question for the study was, "How much support does DWDA have among Oregonians today?" This question was explored at the beginning of the survey, presented before all of the arguments before and against it, in an effort to capture the most neutral response possible. Registered voters were provided with language from the 1994 Oregon ballot "Shall the law allow terminally ill adult patients the voluntarily informed choice to obtain a physician's prescription for drugs to end life?" and asked if they would vote for the question if it were on the ballot today. More than $80 \%$ said they would probably $(n=66,14.9 \%)$ or definitely $(n=289,65.4 \%)$ vote for the question. In contrast, $19.7 \%$ would vote against the measure $(n=19,4.3 \%$ probably no; $n=68,15.4 \%$ definitely no).

\section{Patterns of Support among Subpopulations}

This study explored four secondary research questions, providing context and complexity to the primary question. The first of the follow-up questions asked, "What are the patterns of support in specific subpopulations of Oregonians (e.g. Catholics, 
people of color, Republicans)?" Tables 1, 2, and 3 identify the numbers and percentages of individuals supporting (replying they would definitely or probably vote for death with dignity on the ballot) or not-supporting (replying probably no or definitely no) in each self-reported demographic category.

Interestingly, only one subpopulation among potential Oregon voters featured support below a 50\% majority point: those who indicated they attend church once a week or more often. Every other group had more than a 50\% majority, including those who self-identify as evangelical (support at 55.4\%-44.6\%), mostly Republican (58.1\%49.1\%), conservative (55.4\%-44.6\%). Catholics, a group whose leadership broadly opposed death with dignity, support the law in a 71\%-29\% split. Several groups demonstrate patterns of widespread support: those with no religious affiliation $(99 \%$ $1 \%$ ), those who identify as mostly Democrat or liberal (above $95 \%$ for both), and individuals in rural Congressional Districts 2 and 4 (nearly $90 \%$ for both).

Because of potential underrepresentation among respondents who self-identify as people of color and the relatively few numbers of respondents in these important categories, it is impossible to draw conclusions about support in this important subpopulation.

\section{Comparisons to Prior Years}

The second follow-up research question was: How do the aggregate results from polling in 1994 and 1998 compare to contemporary levels of support in Oregon? In September, 1994, the polling firm of Fairbank, Maslin, Maullin and Associates conducted 
proprietary polling for Oregon Right to Die Political Action Committee (the organization responsible for bringing death with dignity to the Oregon ballot), and in 1997 and 1998, Paul Goodwin of GLS Research conducted proprietary polling for the same committee. The following discussion features comparisons among the three waves of data. No raw datasets were available from which to draw statistical conclusions, rather the information from prior years was derived from private memos and unpublished data tables from the pollsters.

Overall, support has increased over the years from the baseline support poll in 1994 which showed a 59\%-31\% split among voters (Fairbank, Maslin, Maullin, and Associates, 1994). In 1997, support had risen to $61 \%-33 \%$, according to proprietary polls conducted for Oregon Right to Die (Paul Goodwin, personal communication, February 28,1997 , p. 2). One year after the 1997 election, support had risen to $65 \%$, with $32 \%$ of voters indicating they did not support the law (P. Goodwin, personal communication, February 9, 1998, p. 4). The current study found support to be split $80 \%-20 \%$ among Oregon voters, well within the margin of support of an independent 2011 poll (National Journal, n.d.).

If actual results from elections are included as representations of public opinion, then there are a total of six data points from which to draw conclusions about patterns of support for death with dignity in Oregon among potential voters. Table 6 demonstrates support and opposition figures; the question asked in each of these instances was virtually 
the same, "Shall the law allow terminally ill adult patients the voluntarily informed choice to obtain a physician's prescription for drugs to end life?"

Table 6

Support for death with dignity in Oregon between 1994 and 2012*

\begin{tabular}{llcc}
\hline \multicolumn{1}{c}{ Date } & \multicolumn{1}{c}{ Data Derived From } & Support \% & Oppose \% \\
\hline September, 1994 & $\begin{array}{l}\text { Fairbank, Maslin, Maullin, and Associates } \\
\mathrm{n}=700, \text { unpublished polling data }\end{array}$ & $59 \%$ & 31 \\
November, 1994 & Oregon Voters, Election Day & $51 \%$ & $49 \%$ \\
February, 1997 & $\begin{array}{l}\text { GLS Research } \\
\mathrm{n}=600 \text {, unpublished polling data }\end{array}$ & $61 \%$ & $33 \%$ \\
November, 1997 & Oregon Voters, Election Day & $60 \%$ & $40 \%$ \\
February, 1998 & $\begin{array}{l}\text { GLS Research } \\
\mathrm{n}=600, \text { unpublished polling data }\end{array}$ & $65 \%$ & $32 \%$ \\
Summer, 2012 & $\begin{array}{l}\text { Current Study } \\
\mathrm{n}=442\end{array}$ & $80 \%$ & $20 \%$ \\
\hline
\end{tabular}

*For each of these data collection points, virtually the same question was asked, "Shall the law allow terminally ill adult patients the voluntarily informed choice to obtain a physician's prescription for drugs to end life?"

In past polling, several groups of individuals have demonstrated lower levels of support for death with dignity: self-identified Catholics, Republicans, those who identify as coming from an evangelical religious tradition, and people of color. In this survey, support for death with dignity was lower in all subgroups, but there was still majority support for the issue. For Republicans, 55.4\% supported Oregon's law ( $\mathrm{n}=56$ out of 101), as compared to 44\% support in 1993.

Seventy percent of Catholics supported the law in the current study ( $\mathrm{n}=48$ out of 68), and this is substantively higher than $48 \%$ support from the 1993 survey (Fairbank, 
Maslin, Maullin, and Associates, 1994). Nearly 30\% of Oregonians identified as "evangelical" ( $\mathrm{n}=112$ out of 414$)$ with support among the subpopulation of selfidentified individuals from an evangelical tradition running at 55.4\%-44.6\%, this compares to 44\%-56\% support from self-identified protestant evangelicals in 1997 (Paul Goodwin, personal communication, February 28, 1997, p. 7). Among people of color, $68 \%$ supported death with dignity in the current survey, but with underrepresentation among people of color, this number must be viewed with some trepidation. In 1997, underrepresentation limited conclusions about support among people of color, also.

\section{Measuring Opinion Change}

The third follow-up question explored in this study was, "What factors have contributed to changes in public opinion?" Respondents were asked whether or not they had changed their opinions about the law since the first time they became familiar with it. Of the 442 participants, a vast majority reported they had not changed their opinion ( $n=$ $367,83.0 \%) ; 42$ or (9.5\%) recalled having an opinion change on the issue since the first time they were exposed to the issue. Twenty did not recall whether or not their opinions changed and thirteen did not respond to the question ( $4.5 \%$ and $3.0 \%$, respectively).

The subset of respondents reporting an opinion change was asked to describe the direction and magnitude of the opinion change. Most reported a magnitude change, moving from mild to strong support or opposition; few reported a change in direction from oppose or support or the converse. Results are depicted in Table 7. 
Table 7

Magnitude and Direction Change for 36 Respondents Indicating an Opinion Shift Over Time

\begin{tabular}{lll}
\hline & $\mathrm{N}^{\mathrm{a}}$ & $\%$ \\
\hline Mild Support to Strong Support (Magnitude Change) & 20 & $55.6 \%$ \\
Mild Opposition to Strong Opposition (Magnitude Change) & 6 & $16.7 \%$ \\
Oppose to Support (Direction Change) & 6 & $16.7 \%$ \\
Support to Oppose (Direction Change) & 4 & $11.1 \%$ \\
\hline
\end{tabular}

${ }^{a}$ An additional six individuals reported an opinion change, but did not characterize the magnitude or direction of the change.

Respondents were given the opportunity to choose from a variety of reasons why they changed their opinions, and they had the ability to provide a qualitative description for the change. Thirteen had a personal experience leading to opinion change, and one of these individuals provided a description of the experience, "I have had several close family members pass. And, all needed help for suffering." A total of 10 respondents indicated their opinions changed because of a change in personal morals or values, and 6 said the way the law was implemented influenced their opinion change. One respondent said, "Based on data regarding utilization of the law, my opinion is that the law is neither being abused nor is it being overly used. People have this option amongst others when making important and challenging end of life decisions." An additional six individuals said their opinions changed because of the teachings of their church. Three reported seeing something on television or in the newspaper which led them to change opinions, and one person reported following the ideology of a political party.

\section{Factors Predicting Support}

The final research question, "What factors predict support for Death with Dignity? was explored through bivariate and multivariate analysis. Several hypotheses 
were tested to determine factors influencing support for death with dignity among potential voters. Religiosity, education, political party, age, gender, and income were all hypothesized to be related to support.

Many consider religion to be the most impactful variable explaining support or opposition for death with dignity. In this survey, frequency of religious services attendance was explored as a seven-point Likert scale with responses ranging from "never or almost never" to "once a week or more." To determine the relationship between frequency of church attendance and support, a chi-square analysis was conducted. Using this analysis, frequency of church attendance was found to be associated with support, $\chi^{2}(6, n=433)=132.820, p<.001$.

Similarly, a person's affiliation with evangelical traditions is associated with support, as demonstrated by chi-square analysis. A 2 × 2 contingency table analysis was conducted to assess the relationship between support and evangelical tradition, and the results indicated the two variables were significantly related, Pearson $\chi^{2}(1, n=414)=$ 68.396. This test statistic reflects the continuity correction as is appropriate with a $2 \times 2$ analysis. Those individuals who indicated they would vote yes on the measure were significantly less likely to identify as "evangelical" than those who would vote no.

A person's religious affiliation was hypothesized to be related to support. To determine the significance of this relationship, a chi-square analysis was conducted. The six categories of religious affiliation were collapsed to four major categories: Catholic ( $n$ $=68)$, Protestant $(n=144)$, Other $(n=122)$, and None $(n=97)$. In this analysis, religious 
affiliation was significantly associated with support $\chi^{2}(3, n=431)=28.241, p<.05$. In this contingency table, the cells related to "none" were most impactful because of their disproportionate support for death with dignity. Only 1 of the individuals who reported "no religious affiliation" is a non-supporter, the 96 other individuals in this category would support death with dignity at the ballot box. Catholics, Protestants, and "Others" display similar proportions of support for death with dignity.

To compare the relative impact of the three religion-oriented variables, a logistic regression analysis was conducted. The outcome variable was the dichotomized support question with opposition as the reference category, and the predictor variables were evangelical status (dichotomized yes/no response), religious affiliation (Catholic, Protestant, Other, None), and frequency of attendance (collapsed to dichotomized frequent/rare response). The omnibus model was significant $\chi^{2}(3, n=442)=115.669, \mathrm{p}$ $<.001$, and all of the predictor variables were significant in the model (see table 7), but frequency of church attendance with an odds ratio of 9 , was the most impactful in the model. For Oregon voters surveyed, the odds of opposing death with dignity increased by a multiple of 9 for frequent church attendees, when compared to the odds of opposing for rare church attendees.

In some jurisdictions, political party and support are related as Democrats and progressives more likely to vote yes on death with dignity than individuals who identify as conservative or affiliated with the Republican Party. To determine the relationship, a 
chi-square statistic was computed, using only those respondents who indicated they were "liberal," "middle of the road," or "conservative."

Table 8

Logistic Regression Predicting Opposition Using Religiously-Oriented Variables

\begin{tabular}{lllll}
\hline Predictor & $B$ & Wald $\chi^{2}$ & $p$ & Odds Ratio \\
\hline Evangelical & -1.443 & 21.971 & $<.001$ & .236 \\
Religious Affiliation & -.263 & 4.175 & .041 & .768 \\
$\begin{array}{l}\text { Frequency of } \\
\text { Attendance }\end{array}$ & 2.195 & 25.111 & $<.001$ & 8.976 \\
\hline
\end{tabular}

Five respondents identified as a libertarian in the sample, and they were not included in the analysis, because the resulting contingency table failed the assumptions for chi-square due to small expected cells counts. The resulting $3 \times 2$ analysis revealed political affiliation and support for death with dignity were significantly dependent $\chi^{2}(2$, $n=407)=68.681, p<.05$. Conservatives were nearly evenly split on the issue $(n=56$ probably or definitely yes, $n=45$ probably or definitely no), but liberals overwhelmingly supported death with dignity $(n=151$ probably or definitely yes, $n=6$ probably or definitely no). Those who self-identified as "middle of the road" were supportive ( $n=$ 125 probably or definitely yes, $n=24$ probably or definitely no), but not to the same degree as liberals.

Education and age are two variables frequently hypothesized to be associated with support. In this sample, the two variables were not significantly related to support when independents-samples $t$ tests were run. On a six-point ordinal scale with categories ranging from grade school or some high school through graduate or professional degree, 
the mean scores for supporters and non-supporters were very close (3.86 and 3.6, respectively). Similarly, the mean ages for both groups were close (60.6 years and 61.8 years). Neither education and support, nor age and support, were significantly related. Two final demographic variables were explored, gender and income. It was determined through chi-square analysis that gender and support were independent of one another. Men and women tended to support death with dignity in similar proportions. Similarly, income and support were statistically independent of one another in chi-square analysis.

Multivariate analysis. In further consideration of the research question, "What factors predict current support for death with dignity," logistic regression was used to develop three models best predicting the probability of support for the issue. Responses for the outcome variable, support for death with dignity, were collapsed from a four point ordinal scale ranging from strongly support, somewhat support, somewhat oppose, strongly oppose to a dichotomous support/oppose response to meet the requirements of logistic regression. Three regression models were explored: one featuring attitudinal variables, another with demographic variables found to be significant predictors in the bivariate inferential analysis, and a third using attitudinal and demographic variables entered in two separate blocks. The oppose response was the reference category used for all models, meaning the odds ratios reflected the odds of opposing. Similarly, the predicted probability calculations focused on the probability of opposition. 
Multicollinearity was assessed to determine if the predictor variables from all three models were significantly related to each other to the degree they would negatively impact model-building or violate assumptions for binary logistic regression. The regression matrix (see Table 9) indicated there may be some concerns with

Table 9

Correlation Matrix for Model Co-Variates, Pearson's Correlation Values Reported

\begin{tabular}{|c|c|c|c|c|c|c|}
\hline & Govt. & Right & Suicide & Physician & Church & Party \\
\hline Govt & & $.417 * *$ & $.333^{* *}$ & $.286^{* *}$ & $.207 * *$ & -.087 \\
\hline Right & $.417^{* *}$ & & .787 & $.724 * *$ & $.530 * *$ & $-.467 * *$ \\
\hline Suicide & $.333^{* *}$ & $.787 * *$ & & $.772 * *$ & $.496 * *$ & $-.420 * *$ \\
\hline Physician & $.286^{* *}$ & $.774 * *$ & $772 * *$ & & $.420 * *$ & $-.404 * *$ \\
\hline Church & $.207^{* *}$ & $.530 * *$ & $.496^{* *}$ & $.420 * *$ & & $-.371 * *$ \\
\hline Party & -.087 & $-.467 * *$ & $-.420 * *$ & $-.404 * *$ & $-.371 * *$ & \\
\hline
\end{tabular}

**Significant at the $p<.01$ standard, (2-tailed)

multicollinearity among the attitudinal variables, but not with the demographic variables. With three pairs of variables featuring a correlation coefficient larger than .7, there is some evidence of multicollinearity. One of variables creating the most concerns with multicollinearity, opinions about suicide, was included in the second model exploring important attitudinal factors because of the regularity with which they appear in discussions about death with dignity, but dropped out of the final parsimonious model for two reasons. It was a non-significant predictor in the model with attitude variables only, and it created a problem with multicollinearity. Another variable, physician's role, was used in the final model, even though there were issues with multicollinearity between it and the individual right variable. This choice was made because of the regularity with which both variables appear in the literature; however, the results must be interpreted with caution. 
The four attitudinal predictors included in the first model were the role of government (How a terminally ill person chooses to end his/her life should be an individual decision and not a government decision), the question of whether or not death with dignity is an individual right (People in the final stages of a terminal disease should have the right to stop their suffering by hastening their death, if they so choose), the issue of a physician's role in the practice (In general, doctors should never take part in any activity that would help a patient die), and perceptions about suicide (Regardless of circumstances, suicide is morally wrong and the law should not permit it). Throughout this discussion, these variables will be referred to as Role of Government, Individual Right, Physician's Role, and Suicide. Using $t$ tests, all four were found to be significant predictors of support for death with dignity in bivariate analysis.

A model comprising these four predictor variables demonstrated a good fit, according to several measures used to describe goodness of fit in logistic regression. The most straightforward goodness-of-fit measure involves an examination of how often the model predicts support or opposition for the outcome variable in comparison to the null model which assigns $100 \%$ of respondents to the most frequent response (in this case, support). This test produces two classification tables: one using the null model which correctly classified $82.3 \%$ of responses and another the test model using the four attitudinal variables as predictors. This test model was statistically significant $\chi^{2}(4, n=$ $442)=273.359, p<.001$ and produced an overall classification rate of $95.8 \%$, correctly classifying $98.2 \%$ of supporters and $84.7 \%$ of non-supporters. Hosmer and Lemeshow 
(1989) caution against the use of categorization unless the intent of the analysis is categorization, but they have been included here and with the discussion of other models for comparison purposes only. No other interpretations of the categorization tables are offered.

The Hosmer-Lemeshow (H-L) test offers a significance level, a limited, yet important goodness-of-fit measurement. For this test, a well-fitting model will produce a non-significant $p$-value because the null hypothesis for the H-L test can be stated as: there is no difference between observed and expected values in the model. For these data, the H-L test produces a p-value of .691, implying that the model's predicted values are not markedly different from the observed values.

Taken together, these two measures indicate the model is a good fit, but logistic regression offers the opportunity to draw more conclusions about the data than goodness of fit alone. Table 10 depicts the regression coefficients, results of the Wald's test, significance level, and odds ratios for each of the four predictors. An examination of the four predictor variables demonstrates only two are significant predictors in the model at the .05 level: Individual Right and Physician's Role. The Wald statistic, which generally follows a chi-square distribution (Stokes, Davis, and Koch, 1996), is used to determine significance for predictors. For the attitudinal variable Individual Right $Q_{W}=27.411, p<$ .05 ; while $Q_{W}=6.705, p<.05$ for Physician's Role.

Logistic regression includes the calculation of a predicted probability for the outcome variable based on the predictor variables in the equation. These predicted 
Table 10

Logistic Regression Predicting Opposition Using Attitudinal Variables

\begin{tabular}{lllll}
\hline Predictor & $B$ & Wald $\chi^{2}$ & $p$ & $\begin{array}{l}\text { Odds } \\
\text { Ratio }\end{array}$ \\
\hline Role of Government & .451 & 1.014 & .314 & 1.570 \\
Individual Right & 1.787 & 27.411 & $<.001$ & 5.969 \\
Physician's Role & .884 & 6.705 & .010 & 2.422 \\
Suicide & .499 & 2.279 & .131 & 1.647
\end{tabular}

probabilities can be used to explore different scenarios of support or oppose based on the responses to the four predictor variables. For example, an Oregon voter who has few moral qualms about suicide, and who strongly believes death with dignity is an individual right that should not be interfered with by the government while strongly opposing the idea physicians should not help someone die has a predicted probability of .00396 . This means he/she is only three/tenths of one percent likely to oppose death with dignity. Conversely, an Oregon voter who believes suicide is morally objectionable and physicians should not be helping people die, while at the same time opposing death with dignity as an individual right and supporting government intervention in individual decision making has a predicted probability of .99521 ; he/she is $99.5 \%$ likely to oppose.

The odds ratios offer a similar interpretation. In this model, the odds ratios reflect changes in the odds for opposing Death with Dignity. The attitudinal variable, Individual Right, is the most impactful in the model with an odds ratio 5.969, meaning as respondents moved one increment down the scale (i.e. from strongly support to somewhat support) they were six times more likely to oppose Death with Dignity. They were nearly 2.5 times more likely to oppose Death with Dignity as they moved incrementally down the scale conceptualizing a physician's role in helping someone die. 
The second model explored in this analysis featured two demographic variables found to be significant in bivariate inferential analysis: church attendance and political affiliation. The outcome variable was the same dichotomized support variable used in the prior model; the predictor variables were transformed for ease of interpretation. The responses representing frequency of church attendance were transformed to a dichotomous rare/frequent church attendance variable. Individuals attending church once a year or less often were categorized as "rare," and those who attended church every few months to once a week or more were categorized as "frequent." The reference category used in for this variable was "rare church attendee."

For the political affiliation variable, those who reported they were libertarian were dropped from the analysis. Only five individuals self-reported as libertarian, and eliminating this segment of the population from analysis was not impactful because there were not enough libertarians from which to draw generalizable conclusions. The small number of respondents for this category caused problems in the analysis due to cell sizes in the chi-square analyses. SPSS allows for dummy coding of categorical variables in logistic regression, and liberal was chosen as the reference category. Odds ratios are reported for "conservative" and "middle of the road," as a comparison to "liberal."

This second model featuring these demographic variables displayed an adequate fit, according to the goodness-of-fit measures. The omnibus test suggested the model with demographic predictors was significantly different from the null, or intercept only, model $\chi^{2}(2, n=403)=111.736, \mathrm{p}<.001$. However, the null model correctly classified 
$81.6 \%$ of cases, while the test model offered only a slight improvement, correctly classifying $83.6 \%$ of all respondents. The test model was much more successful at classifying supporters $(90.0 \%)$ than opponents (55.4\%). The Hosmer-Lemeshow test returned a non-significant Chi-square $(p=.978)$, suggesting the observed and expected values in the model were not significantly different from one another, the desired outcome for this test.

As was the case in the first model, the exploration of the odds ratios is much more informative than the overall statistics. Table 11 shows the regression coefficients, Wald's tests, significance levels, and odds ratios for variables in this equation. Using a .05 standard, church attendance and both categories of the dummy variable for political affiliation were statistically significant predictors in the model. Looking at the odds ratios, the odds of opposition for frequent churchgoers were ten times higher, relative to the odds of opposition for rare church attendees. For conservatives, their odds of opposition were almost ten times higher, relative to the odds of opposition for liberals; while the odds for opposition for individuals who said they were "middle of the road" were nearly four times higher, relative to the odds of opposition for liberals.

Table 11

Logistic Regression Predicting Opposition Using Demographic Variables

\begin{tabular}{lllll}
\hline Predictor & $B$ & Wald $\chi^{2}$ & $p$ & $\begin{array}{l}\text { Odds } \\
\text { Ratio }\end{array}$ \\
\hline $\begin{array}{l}\text { Church Attendance } * * \\
\text { Political Affiliation }\end{array}$ & 2.337 & 33.223 & $<.001$ & 10.349 \\
$\quad \begin{array}{l}\text { Conservative } \\
\quad \text { Middle of the Road }\end{array}$ & 2.278 & 22.100 & $<.001$ & 9.757 \\
& 1.314 & 7.148 & .008 & 3.719 \\
\hline
\end{tabular}

**Reference category is "rare" church attendee 
In order to calculate odds for different combinations of church attendance and political affiliation among potential Oregon voters, the model was re-run without the dummy coding. Table 12 shows the model-predicted probabilities for all the scenarios based on this predictor equation. Looking at the probability for opposition, this model predicts $56.7 \%$ of all conservative, frequent churchgoers will oppose death with dignity, as compared to $30.5 \%$ of all moderate, frequent churchgoers and $12.8 \%$ of all selfidentified liberal, frequent churchgoers. For all rare church attendees, $10 \%$ of those who identify as conservative oppose death with dignity in this model, as do $4 \%$ of moderates and $1 \%$ of liberals.

Table 12

Model-Predicted Probabilities

\begin{tabular}{lc}
\hline Scenario & Probability for Opposition \\
\hline Conservative Churchgoer & .567 \\
Moderate Churchgoer & .305 \\
Liberal Churchgoer & .128 \\
Conservative Rare Churchgoer & .100 \\
Moderate Rare Churchgoer & .041 \\
Liberal Rare Churchgoer & .013 \\
\hline
\end{tabular}

The final model combined four variables found to be significant in the previous two models, adding the demographic variables of Church Attendance and Political Affiliation in one step and the attitudinal variables Individual Right and Physician's Role in a second step. Overall, this model demonstrated very good fit. The intercept only model correctly categorized $81.7 \%$ of cases, and the addition of the dichotomized church attendance variable and the three level (conservative, middle of the road, liberal) political affiliation variable improved the classification by a slight $2.6 \%$. The first step of the 
model was significant in the omnibus test, $\chi^{2}(2, n=389)=111.658, \mathrm{p}<.001$, with the desired non-significant Hosmer-Lemeshow test.

Adding the attitudinal variables greatly improved the goodness of fit, as demonstrated by the correct classification of $96.1 \%$ of cases. Supporters were correctly classified $98.4 \%$ of the time, while opponents were correctly classified $85.9 \%$ of time. The Hosmer-Lemeshow test was non-significant for the addition of this block of variables. The omnibus test revealed a similar result, $\chi^{2}(4, n=389)=264.157, \mathrm{p}<.001$, indicating the model with both blocks of variables was significantly different from the model with no predictors.

Table 13 shows the intercepts, Wald chi-square values, significance levels, and odds ratios for the six variables in the model. Only three of the individual variables were significant: Church Attendance, Individual Right, and Physician's Role. The variable Individual Right was the biggest predictor with an odds ratio of 7.467 , indicating for every one increment decrease in support for the idea that death with dignity should be a choice for everyone, there was a seven and a half times increase in the odds for

Table 13

Logistic Regression Predicting Opposition Using Demographic and Attitudinal Variables

\begin{tabular}{lllll}
\hline $\begin{array}{l}\text { Predictor } \\
\text { Ratio }\end{array}$ & $B$ & Wald $\chi^{2}$ & $p$ & Odds \\
\hline Church Attendance & 1.267 & 4.020 & $.045^{*}$ & 3.548 \\
Political Affiliation & .131 & .124 & .724 & 1.140 \\
Individual Right & 2.010 & 36.259 & $<.001^{*}$ & 7.467 \\
Physician's Role & .971 & 30.282 & $<.001^{*}$ & 2.641 \\
\hline
\end{tabular}

*Significant at the $p<.05$ standard 
opposition. Church Attendance was the second most important variable in the model, with frequent churchgoers being nearly three and a half times more likely to oppose death with dignity than support it. Finally, holding all other variables constant, ideas about a physician's role were significantly impactful in the model. With an odds ratio of 2.641, for every incremental step to disapproval of the idea that a physician might help someone die, there was a doubling of the odds for opposition.

Notably, holding all the other variables constant, political affiliation was a nonsignificant contributor to this model at the .05 standard. This is an important finding because it runs counter to one of the main hypotheses in this study and to the theoretical model providing the underpinnings for predicting support. According to Stimson's work, political ideology is the biggest predictor of support for controversial social issues in public opinion analysis. Among these respondents, though, frequency of church attendance, perceptions about death with dignity as an individual right, and ideas about a physician's role were significantly better predictors of support than political ideology. 


\section{Discussion}

\section{Chapter 5 Discussion and Conclusions}

The results are consistent with a pattern of growing support for death with dignity in Oregon; currently $80 \%$ of surveyed registered Oregon voters support the law while the remaining 20\% oppose it, compared to prior polling data from 1994 and 1998 indicating the margin of support at 59\%-31\% and 65\%-32\%, respectively (see page $20-23$ for a more thorough discussion of the methods used to obtain these numbers). An examination of subpopulations indicates there is majority support among three different groups traditionally assumed to be split on the issue. As anticipated, the magnitude of support is smaller in these subpopulations than in the general population. More than $60 \%$ of selfidentified Republicans from Oregon support the law, as compared to 44\% in 1993. Seventy percent of Catholics who are registered voters supported the law in the current study, compared to 48\% in 1994 (Fairbank, Maslin, Maullin, and Associates, 1994). Among people of color, $68 \%$ supported death with dignity in the current survey, but with underrepresentation among people of color, this number must be viewed with some caution.

In bivariate inferential analysis, only two clusters of demographic variables were significant predictors of support: those focused on religion and those focused on political affiliation. Age, education, income, and gender were not impactful predictors in this study. In a final parsimonious model, only church attendance, a person's conceptualization of a physician's role, and ideas about death with dignity as an 
individual right were important factors predicting support, holding all other variables constant.

An overall level of support at $80 \%$ appears high in comparison to current polling trends in other states [68\% in Vermont (Castleton, 2013); 56\% in Massachusetts (Public Policy Polling, 2012)], but given the state's policy history, one reasonably might expect support to be higher in Oregon than in any other jurisdiction or state in the country. The most recent independent polling of the state's populace, conducted in 2011 by The National Journal and the Regence Foundation, found support for Oregon's Death with Dignity Act at 77\% (n.d.). The independent finding from researchers with The National Journal falls within the margin of error of the current study, suggesting there may be stability at the $75 \%-80 \%$ range.

Holding all other variables constant, the only demographic variable predicting support was frequency of church attendance. Some sources point to denomination or faith tradition as impacting opinions about death with dignity and euthanasia with Catholics being identified uniformly as opponents (Purvis, 2012; Stutsman, 2004). Among, this study's respondents, frequency of church attendance was a more important predictor of support than religious affiliation. Indeed, a majority of self-identified Catholics supported Oregon's law, but a majority of frequent churchgoers did not.

Those who oppose death with dignity grapple with the idea of a physician participating in any act that would help a patient die. Opinions about this concept have a statistically significant impact on support. Interestingly, a recent article in the New 
England Journal of Medicine (Julian, Prokopetz,\& Soleymani Lehmann, 2012) advocated a re-vamped standard of care, removing individual physicians from the process and replacing them with a federal or state entity which would, "confirm the authenticity and eligibility of patients' requests, dispense medication, and monitor demand and use," (p. 99). This policy reform suggestion did not enjoy much support, as evidenced by lack of public discussion and political advocacy, but it addressed the core ethical concern of whether or not physicians should participate in activities which intentionally lead to death.

Supporters embraced the concept of death with dignity as an individual rightsupporting the idea that those who are terminally ill should have a right to hasten their death if they so choose. In the final model, this point of view more closely predicted support than any other variable. Contextualizing this issue as an individual right is not common in the literature, but both the Massachusetts chapter of the National Association of Social Workers (NASW-MA) and the Massachusetts chapter of the American Civil Liberties Union (ACLU-MA) supported the 2012 death with dignity ballot initiative using this type of language. According to an article in the NASW-MA newsletter, "Let's work together to support this distinctly human right — the right for terminally ill patient to make voluntary and informed decisions at end of life," (Kozin, 2012, p. 8). It is feasible for policy reform advocates to more clearly explore the complex concepts embedded in the idea of death with dignity, as they might shed light on sentiments or attitudes underlying support for the issue. Certainly, other issues have experienced success by 
calling attention to an individual right unprotected by the status quo (e.g. LGBT marriage equality and abortion)

Beyond predicting overall support and factors related to support, this study attempted to uncover explanations for any opinion changes over time. Fewer than $10 \%$ of respondents indicated they had an opinion change since the first time they were exposed to or thought about the issue. Most registered Oregon voters reporting an opinion change suggested the change was one of magnitude: of moving from mild support to strong support or moving from mild opposition to strong opposition. Only ten respondents suggested they switched from support to opposition or vice versa. Similarly, when asked if they had voted for or against death with dignity on the ballot, $73 \%$ indicated they had voted for the law; $20 \%$ against. These findings suggest opinion on the issue has been markedly stable over time in terms of both past voting habits and directed recall of opinion change.

It appears this study was more successful at describing the stability of opinion than factors leading to opinion change. With so few individuals responding affirmatively to questions of opinion change, an analysis of their replies was compromised by the small number of responses. Respondents identified personal experiences, the implementation experience, and teaching of their church as the most common reasons for opinion change; however, as noted later in this chapter, a qualitative analysis of opinion change is warranted to explore more deeply the question of why opinions change. 
In one sense, the stability finding and the pattern of growth in support may seem somewhat contradictory: how can overall levels of support increase by 15 points over the last 20 years, but remain stable at the same time in the mind of individual voters?

Problems related to recall, response bias, and representativeness of the sample might be legitimate explanations rising from statistical or methodological factors. New voters moving to the state or the deaths of a cohort of non-supporters as postulated by the agestability hypothesis (see literature review) are reasonable explanations. The most plausible explanation may arise out of looking at this phenomenon as a duality: there is a pattern of growing support and support is stable. Approximately $80 \%$ of registered Oregon voters support the law; nearly all voters, opponents and supporters, have stable opinions of the law, ultimately raising the question of whether the perceived positive experience of implementation, passage of time, personal experiences, or lack of controversy have acted to both reaffirm support and strengthen it at the same time.

An exploration of these findings through the lens of Stimson's Issue Evolution Theory suggests there is some evidence supporting Stimson's ideas of issue alignment, but in no way may the evidence be deemed direct or clear-cut. For example, Stimson posits political affiliation as the primary factory predicting support for controversial issues; and, these findings demonstrate frequency of church attendance is the primary demographic factor predicting support—not political affiliation, as suggested by Stimson. While political affiliation is an important contributing predictor variable in some models; 
in a model featuring attitudinal variables, political affiliation, and church attendance, political affiliation drops out of the cluster of significant predictor variables.

Stimson suggests the issue becomes more polarized over time between the political parties; yet, these data suggest death with dignity is supported by both parties. It is polarized in the sense of one party supporting it more than the other (92\% support from Democrats versus $62 \%$ support from Republicans), but not in the sense of one party supporting it and the other opposing it.

Interestingly, during a recent hotly-contested ballot initiative in the Commonwealth of Massachusetts, opponents to death with dignity ran a campaign suggesting this issue was not a progressive one. In a New York Times op-ed, a leader on President Obama's healthcare policy team, Ezekiel Emanuel, argued death with dignity was of primary benefit to the wealthy, educated elite and would be used against the poor (2012). E. J. Dionne (2012), an editorial writer for The Washington Post, published a piece entitled, "Liberals Should be Wary of Assisted Suicide." A palliative care physician, Ira Byock (2012), published an article in the Atlantic Monthly calling himself a "card-carrying progressive" opposed to Death with Dignity.

The most important consideration regarding Stimson's theory seems to be time. His conclusions came after an examination of support for 7 issues over a 50-year period. Arguably, these data about death with dignity were collected at the midpoint of his timeframe, and another 25 years would have to elapse before his model could be more appropriately applied. Another factor seems relevant: at least one of the issues 
experienced a Supreme Court case deciding policy on the national level (Roe v. Wade) and eliminating some need for a state-by-state approach. Such has not been the case for death with dignity, and it begs the question whether federal court decisions have an impact on public opinion in a manner unexplained in Stimson's theory.

\section{Limitations}

Internal validity is of concern in this study due to the pre-experimental nature of the design. This research design with only one wave of data and no control group had low internal validity, and threats to internal validity related to history, maturation, and statistical regression were not subjected to controls. While the study did not set out to establish causality or make causal inferences, threats to internal validity are worthy of mention.

The instrument itself may have been a source of limitations due to measurement error. This is a fairly common challenge in survey research, as illustrated by Rubin \& Babbie (2005), "Survey research is generally weak on validity and strong on reliability...the artificiality of the survey format constrains validity. As an illustration, people's opinions on issues seldom take the form of strongly agreeing, agreeing, disagreeing or strongly disagreeing with a particular statement," (p. 303). The concepts of "Death with Dignity," political affiliation, and religiosity are complex phenomena and the response categories noted by Rubin and Babbie above may not have adequately captured a respondents' opinions or attitudes toward these concepts. 
Systematic bias caused by social desirability bias and/or recall bias may have been a source of measurement error in this study. One of the main research questions sought to understand the factors which led respondents to change their opinions about DWDA through the years. In order to answer this question, respondents were asked whether or not they had changed their opinions about DWDA. Social desirability bias may have led respondents to reply "no," because they do not want to be viewed as individuals who voted against the law which has become more popular through the years. In addition, recall bias might have impacted their responses, as those surveyed might not remember how they voted, if they voted, and the reasons why their opinions may have changed. Steps were taken to reduce both types of bias, including attention paid to the order of questions and rotation of nominal response categories. Regardless of the steps taken to mitigate the bias, the retrospective nature of this line of questioning may have led to systematic bias in measurement.

Perhaps the biggest limitation of this study is the lack of representativeness in certain categories of voters, or more precisely, lack of data from which to draw conclusions about representativeness; thereby limiting the generalizability of its findings. Looking at US Census Bureau data, women may be overrepresented among respondents; young voters may be underrepresented. While there appears to be good geographic dispersion of respondents, there may be lack of representation among people of color. The lack of representativeness is likely due to several factors: the issue which in some cases is a taboo subject, the proliferation of cell phones, and Oregon's status as having a 
longstanding Death with Dignity law, while other states have no such legislation. Death is not a palatable issue to many, and discussions of death are rare (Smith, 2000). Some sociologists have gone so far as to assert that we have a death-denying culture, or a death taboo, tacitly discouraging individuals from engaging with others about death (Lee, 2008). It is impossible to know if more or different individuals would have responded, had they received a survey about a different topic.

The proliferation of cell phones and the demise of the home "landline" phone mean that data collection methods relying on a traditional phone survey model are limited. Tentative research in this area demonstrates individuals in cell phone only homes are substantively different than those with landlines (Dillman, Smyth, and Christian, 2009). Pollsters are now relying on random digit dialing and cell phone number extrapolation strategies to reach this population. Such strategies were economically unfeasible for this project, but other strategies were used to address the issue including offering an online survey instrument. Utilization of newer technologies likely would have increased the number of males and those under 30 in the pool of survey respondents, thereby increasing the generalizability of the findings.

Finally, Oregon has had Death with Dignity legislation since 1997; Washington since 2008. No other state in the United States has such a law; and, therefore, patterns of support among Oregonians may be different from those in other states because of their longstanding experience with the law. This data likely would not be appropriately used to estimate levels of support in other states at this point; rather it would be better used at 
predicting future patterns of support in states considering end-of-life care policy reform like Death with Dignity.

\section{Implications for Future Research}

Several issues stand out as worthy of future research. First, this project attempted to address the question of how and if opinion changed over time. Because so few respondents indicated an opinion change, no statistical conclusions could be drawn, and a qualitative approach may be warranted. Focus groups made up of "opinion changers" or a narrative analysis of personal stories might provide more insight into why and how people changed their opinion over time on the issue. A quantitative approach with a larger sample of "opinion changers" could address the same concern.

Similarly, a tacit question explored in this research, one focused on whether or not the status of Oregon's law as a reified policy in existence for 15 years had any impact on opinion change, could not be fully addressed with this quantitative analysis. During the data collection process, respondents were not prompted to answer the opinion change question to this effect because there was no indication in prior literature that it was a legitimate response. Different approaches using qualitative analysis might be more successful at exploring the concept of how a law becomes legitimized over time in the eyes of the people.

A third issue to be explored involves the differences in support arising because of events in the media or the public eye versus some static level of support. This survey was distributed during a time of little public activity on the issue, but when a divisive 
campaign is being waged or a controversial public figure like Jack Kevorkian is active, public opinion shifts. With twenty years of public opinion polling on the issue, an unanswered question about this static level of support remains. Is there some level or percentage of support which remains unchanged, even in the face of public controversy and what are the patterns of such support? These are two relevant questions, worthy of exploration in future research.

Finally, the four attitudinal issues commonly explored in research and in the media (Role of Government, Individual Right, Physician's Role, and Suicide) were examined using a single question only. Further research into these concepts is merited, as singly the questions may be reductive. These four questions explore complex constructs using a single question, and scale development and/or exploration into the various dimensions of each of these concepts would represent an important contribution to the literature in this area.

\section{Implications for Policy and Practice}

According to Wyers (1991), social work policy-practitioners must possess a specialty set of skills within social work to appropriately complete their job tasks. For those social workers involved in social justice movements advocating for policy reform through the enactment of legislation or ballot measures, expertise in polling is an important skill. These social workers must be able to effectively communicate their thoughts and ideas to the general public through the media, challenging the dominant discourse and reframing their issue of interest in a manner consistent with social work 
values. Polling is critical because it provides insight into the general public's response to the reframing process. It can help to answer questions such as: who is the most effective messenger to challenge the dominant discourse in our community?, how will our community respond to social work values being placed above others?, and is the community amenable to a reframe of the issue? Knowing answers to these questions is critical to running a campaign to challenge the dominant discourse.

Many social workers are involved in participatory action or empowerment research with groups they serve, in an effort to use data and research findings to move a social justice agenda forward. Public opinion research, including an exploration of how opinion changes, about social justice issues, is an important skillset social workers could bring to a social justice movement. The methods used in this study are replicable for a variety of social justice issues, and social workers should feel empowered to use their data analysis and research methods skills to participate in or lead efforts to study public opinion. Skill at public opinion research is a valuable tool social work policypractitioners can bring to a group of individuals interest in social change, and this study can act as an affordable and achievable model.

In terms of direct application to policy, these results are relevant to all individuals, social workers or not, involved in death with dignity policy reform efforts. Support has grown in Oregon since the initial passage of the law, and there are few abnormalities in the sample which suggest other states would have a different experience. It is feasible individuals from other states might exhibit the same traits as respondents in this study- 
demonstrating growing support over time with general levels of stability in peoples' minds. Like those from Oregon, individuals from other states may not experience vacillation in their opinions about death with dignity over time. Lawmakers, legislators, or policy reform advocates may find this idea of future growth and stability helps to answer some of their concerns about the issue.

The findings from this study have implications for all types of social workers in Oregon, including those practicing in fields unrelated to polling. These numbers and those from another poll undertaken in the same time period indicate that a firm majority of voting individuals served by social workers support death with dignity. With widespread support and a 15 -year history of implementation, it seems likely social workers in Oregon will encounter individuals interested in using the processes involved in the DWDA. While the correlation between support and usage was not studied here, high levels of support suggest social workers in Oregon should have some familiarity with the law so they can be a resource for individuals interested in the law. Similarly, social workers who are not supportive of the law should be prepared to make referrals to social workers or organizations willing to discuss the policy with those in need. Such referrals allow social workers opposed to this law to meet their ethical obligation of nonabandonment.

Another suggestion for practice found in these results focuses on social work education. Frequently, death with dignity is presented to students as a controversy or an ethical dilemma, yet these findings suggest the people of Oregon are not conflicted, in 
general, by the law. They maintain stable opinions, either in support or opposition, and exhibit little vacillation in their beliefs. If the take-away message for social work practitioners exposed to this issue during coursework or seminars is "death with dignity is a controversial policy," they may encounter different opinions in practice. Certainly, exploration of death with dignity through an ethical dilemma lens is valid for social work education, but in Oregon, the lens should be expanded. Most Oregonians support the issue and exhibit little need for guidance in examining this issue as an ethical dilemma.

\section{Conclusions}

This study focused on voter public opinions about the Oregon Death with Dignity Act, viewing support partially through the lens of the Issue Evolution Theory and finding the current margin of support in Oregon to be $80 \%-20 \%$. This cross-sectional research study found support to be approximately 20 points higher than it was in Oregon in 1998 after the second ballot initiative enacting the policy. Historically-opposed subpopulations (Republicans, frequent churchgoers, and people of color) exhibited majority support. The main factors predicting support were frequency of church attendance, opinions about the role of physicians in prescribing lethal medications, and ideas about this issue as a personal choice or individual right. Issue Evolution Theory suggests political affiliation eventually becomes the main predictor of support for controversial issues, but this theoretical tenet was not supported by the research findings.

Furthermore, Oregonians reported their opinions on the issue have remained stable over time with few individuals indicating they had changed their opinion on the 
issue since the first time they thought about it. This finding must be viewed with some skepticism, though, as recall bias may partially or fully explain this finding.

These findings have important implications for policy and practice, as well as future research. Lawmakers and stakeholders involved with death with dignity policy reform in other jurisdictions may find these findings informative and useful in guiding the decision-making process. Social workers in Oregon may encounter widespread support for the issue, with few individuals experiencing the issue as a personal ethical dilemma. They should be prepared to act as an informed resource or provide appropriate referrals. Finally, future research recommendations include the exploration of dimensions related to death with dignity as an individual right and an examination of those who have changed their opinions, using qualitative methods or a bigger sample. 


\section{References}

Aid in dying, Oregon style. [Editorial]. (2008, September 21). The Sunday Oregonian, p. E4.

Allen, J., Chavez, S., DeSimone, S., Howard, D., Johnson, K., LaPierre, L.,...Sander, J. (2006). Americans' attitudes toward euthanasia and physician-assisted suicide, 1936-2002. Journal of Sociology \& Social Welfare, 33(2), 5-23.

American Association of Public Opinion Research, (2009). Survey disclosure checklist. Retrieved from http://www.aapor.org/Survey_Disclosure_Checklist1.htm on 11/28/2012Andersen, R., \& Fetner, T. (2008). Cohort differences in tolerance of homosexuality: Attitudinal change in Canada and the United States, 1981-2000. Public Opinion Quarterly, 72(2), 311-330.

Angell, M. (1999). Caring for the dying - Congressional mischief [Editorial]. New England Journal of Medicine, 341(25), 1923-1924.

Angell, M. (1997). The Supreme Court and physician-assisted suicide - The ultimate right [Editorial]. The New England Journal of Medicine, 336(1), 50.

Arceneaux, K. (2002). Direct democracy and the link between public opinion and state abortion policy. State Politics \& Policy Quarterly, 2(4), 372-387.

Arnold, R. D. (1990). The logic of congressional action. New Haven, CT: Yale University Press.

Booth Gardner's final campaign. [Editorial]. (2008, January 13). The Sunday Oregonian, p. E4. 
Bruce, C. R. (2012). “In love with easeful death:” Review of the film 'How to Die in Oregon' [Film Review]. The American Journal of Bioethics, 12(12), 66-67.

Burstein, P. (2003). The impact of public opinion on public policy: A review and an agenda. Political Research Quarterly, 56(1), 29-40.

Burstein, P., \& Linton, A. (2002). The impact of political parties, interest groups, and social movement organizations on public policy: Some recent evidence and theoretical concerns. Social Forces, 81(2), 381-408.

Byock, I. (2012, October 25). Physician-assisted suicide is not progressive. The Atlantic. Retrieved from http://www.theatlantic.com

Campbell, D, \& Stanley, J. (1963). Experimental and quasi-experimental designs for research. Chicago: Rand-McNally.

Carroll, J. (2006, June 19). Public continues to support right-to-die for terminally ill patients [Press release]. Retrieved from http://www.gallup.com/poll/23356/Public-Continues-Support-RighttoDieTerminally-Ill-Patients.aspx.

Castleton Polling Institute. (2013). Castleton polling results. Retrieved from http://www.castleton.edu/polling/feb20_2013/pollresults.htm

Center for American Women and Politics. (2011). Gender Differences in Voter Turnout. Retrieved from http://www.cawp.rutgers.edu/fast_facts/voters/documents/ genderdiff.pdf 
CNN. (November 4, 2008). Exit polls: Washington Initiative 1000. Retrieved from http://www.cnn.com/ELECTION/2008/results/polls/\#WAI01p1

Coleman, D. (2002). Not dead yet. In K. Foley \& H. Hendin (Eds.) The case against assisted suicide: For the right to end-of-life care (pp. 213-237). Baltimore, MD: Johns Hopkins University Press.

Converse, P. E. (1964). The nature of belief systems in mass publics. In. D. E.. Apter (Ed.) Ideology and discontent (pp. 75-101). Ann Arbor, MI: University of Michigan Press.

Cruzan v. Missouri Department of Health. 497 U.S. 261. (1990).

Dillman, D. A., Smyth, J. D., \& Christian, L. M. (2009). Internet, mail, and mixed-mode surveys: The tailored design method $\left(3^{\text {rd }}\right.$ ed.). Hoboken, NJ: John Wiley \& Sons.

Dionne, E. J. (2012, November 1). Liberals should be wary of assisted suicide. The Washington Post. Retrieved from http://www.washingtonpost.com

Duncan, O. D., \& Parmelee, I. F. (2006). Trends in public approval of euthanasia and suicide in the US, 1947-2003. Journal of Medical Ethics, 32, 266-272.

Emanuel, E. (2012, October 27). Four myths about doctor-assisted suicide. The New York Times. Retrieved from http://nytimes.com

Facchini, G., \& Mayda, A. M. (2008). From individual attitudes towards migrants to migration policy outcomes: Theory and evidence. Economic Policy, 23(56), 651713. 
Fairbank, Maslin, and Maullin Associates. (1994). [Polling data regarding Oregon Measure 16]. Unpublished raw data.

Ganzini, L. (2004). The Oregon experience. In T. E. Quill, \& M. P. Battin (Eds.), Physician-assisted dying: The case for palliative care and patient choice (pp. 165-183). Baltimore, MD: The Johns Hopkins University Press.

Green, S. B., \& Salkind, N. J. (2005). Using SPSS for Windows and Macintosh: Analyzing and understanding data $\left(4^{\text {th }}\right.$ ed.). Upper Saddle River, NJ: Pearson.

Haider-Markel, D. P., \& Joslyn, M. R. (2008). Beliefs about the origins of homosexuality and support for gay rights: An empirical test of Attribution Theory. Public Opinion Quarterly, 72(2), 291-310.

Harris Interactive. (2005). Majorities of U.S. Adults Favor Euthanasia and PhysicianAssisted Suicide by More than Two-to-One. Retrieved from http://www.harrisinteractive.com/harris_poll/index.asp?PID=561

Hicks, G. R., \& Lee, T. T. (2006). Public attitudes toward gays and lesbians: trends and predictors. Journal of Homosexuality, 51(2), 57-77.

Ho, S. S., Brossard, D., \& Scheufele, D. A. (2008). Effects of value predispositions, mass media use, and knowledge on public attitudes toward embryonic stem cell research. International Journal of Public Opinion Research, 20(2), 171-192.

Gallup, (2007). Public Divided Over Moral Acceptability of Doctor-Assisted Suicide. Retrieved from http://www.gallup.com/pol1/27727/Public-Divided-Over-MoralAcceptability-DoctorAssisted-Suicide.aspx. 
Hosmer, D. W., \& Lemeshow, S. (1989). Applied logistic regression. New York: John Wiley \& Sons.

John Paul II. (1995). Evangelium vitae. Retrieved from http:/www.vatican.va/edocs/ ENG0141/_INDEX.HTM.

Julian J.Z., Prokopetz, B.A., \& Soleymani Lehmann, L. (2012). Redefining physicians' role in assisted dying. New England Journal of Medicine, 367, 97-99. doi: 10.1056/NEJMp1205283

Kingdon, J. W. (2003). Agendas, alternatives, and public policies ( $2^{\text {nd }}$ ed.). New York: Longman.

Kozin, K. (2012, September). Supporting death with dignity. NASW Massachusetts Chapter Focus Newsletter. Retrieved from www.naswma.org/displaynewsletter .$c f m$

Lascher, E. L., Hagen, M. G., \& Rochlin, S. A. (1996). Gun behind the door: Ballot initiatives, state polices and public. Journal of Politics, 58(3), 760-775.

Law, S. A. (2004). A political and constitutional context. In T. E. Quill, \& M. P. Battin (Eds.), Physician-assisted dying: The case for palliative care and patient choice (pp. 300-308). Baltimore, MD: The Johns Hopkins University Press.

Lee, R. L. (2008). Modernity, mortality and re-enchantment: The death taboo revisited. Sociology, 42(4), 745-759. 
Mackelprang, R. W., \& Mackelprang, R. D. (2005). Historical and contemporary issues in end-of-life decisions: Implications for social work. Social Work, 50(4), 315324.

National Association of Social Workers. (2008). Code of Ethics. Retrieved from http://www.socialworkers.org/pubs/code/code.asp

National Journal. (n.d.). Living well at the end of life poll - Topline results. Retrieved from http://syndication.nationaljournal.com/communications/ NationalJournalRegenceSeattleToplines.pdf.

Nisbet, M. C. (2005). The competition for worldviews: Values, information, and public support for stem cell research. International Journal of Public Opinion Research, 17(1), 90-112.

Norton, E. M., \& Miller, P. J. (2012). What their terms of living and dying might be: Hospice social workers discuss Oregon's Death with Dignity Act. Journal of Social Work in End-of-Life \& Palliative Care, 8, 249-264. doi: $10.1080 / 15524256.2012 .708295$

Ogden, R. D., \& Young, M. G. (2003). Washington State social workers' attitudes toward voluntary euthanasia and assisted suicide. Social Work in Health Care, 37(2), 4370.

Oregon Employment Department. (2011). 2010 Census Tells Us How Old We Are. Retrieved from http://www.olmis.org/olmisj/ArticleReader? itemid $=00007708 \# \mathrm{Graph} \% 201$ 
Oregon Health Authority. (2013a). Oregon's Death with Dignity Act-2012. Retrieved from http://public.health.oregon.gov/ProviderPartnerResources/ EvaluationResearch/DeathwithDignityAct/Documents/year15.pdf

Oregon Health Authority. (2013b). Prescription History-Oregon Death with Dignity Act. Retrieved from http://public.health.oregon.gov/ProviderPartnerResources/ EvaluationResearch/DeathwithDignityAct/Documents/prescriptionhistory.pdf Oregon Health Authority. (2013c). Death with Dignity Act History. Retrieved from http://public.health.oregon.gov/ProviderPartnerResources/EvaluationResearch/De athwithDignityAct/Documents/history.pdf

Oregon Secretary of State. (2012). 2012 Monthly Voter Registration Statistics. Retrieved from http://oregonvotes.org/pages/history/stats/12mvr.html

Page, B. I., \& Shapiro, R. Y. (1983). Effects of public opinion on policy. The American Political Science Review, 77(1), 175-190.

Preston, T. (2006). Patient-directed dying: A call for legalized aid in dying for the terminally ill. New York: Iuniverse Publishing.

Public Policy Polling. (2012). Warren lead up to 6 points, Obama's down to 14. Retrieved from http://www.publicpolicypolling.com/pdf/2011/ PPP_Release_MA_10112.pdf\#page=2

Purvis, T. E. (2012). Debating death: Religion, politics, and the Oregon Death with Dignity Act. Yale Journal of Biology and Medicine, 85(2), 271-284. 
Quill, T. E. (1991). Death and dignity: A case of individualized decision making. New England Journal of Medicine, 324(10), 691-694.

Quill, T. E., \& Cassel, C. K. (2004). Nonabandonment: A central obligation for physicians. In T. E. Quill, \& M. P. Battin (Eds.), Physician-assisted dying: The case for palliative care and patient choice (pp. 24-38). Baltimore, MD: The Johns Hopkins University Press.

Quill, T. E. (2012). Physicians should "Assist in suicide" when it is appropriate. Journal of Law, Medicine \& Ethics, 40(1), 57-65.

Rubin. A, \& Babbie, E. R. (2005). Research methods for social work (5th ed.). Belmont, CA: Brooks/Cole.

Smith, R. (2000). A good death: An important aim for health services and for us all [Editorial]. British Medical Journal, 320, 129-130.

Snow, D. A. (2012). Framing and social movements. The Wiley Blackwell encyclopedia of social and political movements. Retrieved from http://onlinelibrary. wiley.com/doi/10.1002/9780470674871.wbespm434/abstract

Steinbrook, R. (2008). Physician-assisted death - from Oregon to Washington State. New England Journal of Medicine. 300(24), 2513-2515. doi: 10.1056/NEJMp0809394

Stimson, J. A. (2004). Tides of consent: How public opinion shapes American politics. New York: Cambridge University Press. 
Stimson, J. A., MacKuen, M. B., \& Erickson, R. S. (1995). Dynamic representation. American Political Science Review, 89, 543-565.

Stokes, M. E., Davis, C. S., \& Koch, G. G. (1995). Categorical data analysis using the SAS system. Cary, NC: SAS Institute, Inc.

Stutsman, E. D. (2004). Political strategy and legal change. In T. E. Quill, \& M. P. Battin (Eds.), Physician-assisted dying: The case for palliative care and patient choice (pp. 245-263). Baltimore, MD: The Johns Hopkins University Press.

Tolle, S. W., Tilden, V. P., Drach, L. L., Fromme, E. K., Perrin, N. A., \& Hedberg, K. (2004). Characteristics and proportion of dying Oregonians who personally consider physician-assisted suicide. The Journal of Clinical Ethics, 15(2), 111122.

U.S. Census Bureau. (n.d.). State and County Quick Facts. Retrieved from http://quickfacts.census.gov/qfd/states/41000.html

U.S. Election Assistance Committee. (2011). 2010 election administration and voting survey: A summary of key findings. Retrieved from http://www.eac.gov/ assets/1/Documents/990-281_EAC_EAVS_508_revised.pdf

Voters' pamphlet: State of Oregon special election-November 4, 1997. (n.d.) Retrieved from library.state.or.us/repository/2009/200912301518203/sp1997_11_4.pdf

Washington v. Glucksberg. 521 U.S. 702 (1996).

Webb, M. (1999). The good death: The new American search to reshape the end of life. New York: Bantam Books. 
Wiecko, F. M., \& Gau, J. M. (2008). Every life is sacred...kind of: Uncovering the sources of seemingly contradictory public attitudes toward abortion and the death penalty. The Social Science Journal, 45(4), 546-564.

Wyers, N. L. (1991). Policy-practice in social work: Models and issues. Journal of Social Work Education, 27(3), 241-251.

Zaller, J. R. (1992). The nature and origins of mass opinion. New York: Cambridge University. 


\section{Appendix}

\section{Oregon Death with Dignity Act Survey}

Your participation is voluntary. Because some questions relate to death, it's possible you could feel some discomfort. You can skip any questions. You will not benefit directly from participation, but your answers will help us get a better understanding of what people think about death with dignity since the law passed. Your responses will be confidential, and your responses will be associated with a code number and not your name. By answering the questions and mailing in the survey you are giving your consent to participate.

1.) Are you registered to vote in Oregon at the present time?

$\bigcirc$ Yes

No

2.) How frequently do you vote on ballot measures?

Always

Usually

Sometimes

Usually Not

Fifteen years ago, the voters of Oregon approved ballot Measure 16, which asked, "Shall the law allow terminally ill adult patients the voluntarily informed choice to obtain a physician's prescription for drugs to end life?"

3.) Thinking about today, how would you vote on this measure if it appeared on the ballot?
$\bigcirc$ Definitely Yes
Probably Yes
Probably No
Definitely No

4.) Based on what you may have seen or heard, how do you think this law is working?
Very Well
Somewhat Well
Neither Well Nor Badly
Somewhat Badly
Very Badly

5.) How much do you know about the Death with Dignity Act?

Very Familiar, I know a lot about the law

Somewhat Familiar, I know the basic idea about how it works.

A Little, I've heard about it, but don't know much about how it works.

Not Familiar, This is the first time I've heard

about it.

6.) Please think about the first time you became familiar with this law. Have you changed your opinion about the law since then?

Yes (CONTINUE)

No (Go to Question 9.)

Don't Recall (Go to Question 9.)

7.) Which statement best describes the direction in which your opinion has changed?

From Support To Strong Support

From Mild Opposition To Strong Opposition

From Support To Oppose

From Oppose To Support

8.) Please share some of the reasons why you have changed your opinion. You may select multiple categories or provide your own response.

I saw something in the newspaper or television that led me to change my opinion 
The way the law has been implemented has influenced my opinion.

I'm following my political party

I've had a personal experience

I'm following the opinions of public and/or elected officials

My personal morals and/or values have changed

The teachings of my church

Other--Please explain other factors which have led you to change your opinion:
9.) How important to you is this issue of whether or not to allow terminally ill adult patients the voluntarily informed choice to obtain a physician's prescription for drugs to end life?

Not Important

Somewhat Important

Important

Quite Important

Very Important

10.) People express different opinions about issues having to do with people who are dying of a terminal disease. Which of the following statements come closer to your point of view? If I am terminally ill with no hope of recovery, the decision about when I end my suffering is my own to make Only God should decide when my life ends

11.) How a terminally ill person chooses to end his/her life should be an individual decision and not a government decision.
Strongly Agree
Somewhat Agree
Somewhat Disagree
Strongly Disagree

12.) People in the final stages of a terminal disease should have the right to stop their suffering by hastening their death, if they so choose.
Strongly Agree
Somewhat Agree
Somewhat Disagree
Strongly Disagree

13.) Regardless of circumstances, suicide is morally wrong and the law should not permit it.
Strongly Agree
Somewhat Agree
Somewhat Disagree
Strongly Disagree

14.) In general, doctors should never take part in any activity that would help a patient die.
Strongly Agree
Somewhat Agree
Somewhat Disagree
Strongly Disagree

15.) The Death with Dignity Act has been on the Oregon ballot twice, once in 1994 and once in 1997. Have you ever had the opportunity to cast a vote for or against the Death with Dignity Act?
Yes (Go to Question 16.)
No (Skip to Question 17.)
Don't Recall (Skip to Question 17.)

16.) For informational purposes only, how did you vote for Death with Dignity on the Oregon ballot?
I Voted For It
I Voted Against It
I Chose Not To Vote
I Don't Recall

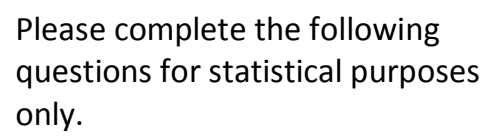
questions for statistical purposes only. 
17.) What category best describes your racial/ethnic identity?

White

African American Or Black

American Indian

Asian

Native Hawaiian Or Pacific Islander

Hispanic Or Latino

Two Or More Races

Other (Please Specify:

18.) How often do you attend religious services?

Never Or Almost Never

$\bigcirc$ Less Than Once A Year

About Once A Year

Every Few Months

About Once A Month

A Few Times A Month

Once A Week Or More

19.) What's your religious affiliation?

Catholic

Protestant

Jewish

Mormon

Other (Specify:

None

20.) How would you describe your point of view in terms of the political parties?

Mostly Democrat

Leaning Democrat

Completely Independent

$\bigcirc$ Leaning Republican

Mostly Republican

None

21.) What is the last grade you completed in school?

$\bigcirc$ Grade School Or Some High School
High School Graduate

Technical / Vocational School or

Some College (2-Yr.)

$\bigcirc$ College Graduate (4-Yr.)

Some Graduate School

Graduate Or Professional Degree

22.) How would you describe yourself

politically?

Conservative

Middle Of The Road

$\bigcirc$ Liberal

Libertarian

23.) Do you consider yourself to be

evangelical

or born again?

$\bigcirc$ Yes

No

24.) What was your total income for your household before taxes in 2010?
$\$ 10,000$ Or Less
$\$ 10,001-14,999$
$\$ 15,000-24,999$
$\$ 25,000-34,999$
$\$ 35,000-49,999$
$\$ 50,000-74,999$
$\$ 75,000-99,000$
$\$ 100,000$ or More

25.) What is your gender?

Male

Female

Other

26.) What is your year of birth?

$\bigcirc$ (Specify: 19_)

\section{THANK YOU}

Your Response is appreciated.

Please take a moment now to return this survey in the postage-paid return envelope. 